\title{
Research Paper \\ Designing an ERP System by Adopting the Decision Tree Algorithm: A Case Study in the General Company of Oil Products Distribution.
}

Journal of

\section{TANMIYAT AL- RAFIDAIN \\ (TANRA)}

A scientific, quarterly, international, open access, and peer-reviewed journal

Vol. 40, No. 130

June 2021

(C) University of Mosul | College of Administration and Economics, Mosul, Iraq.

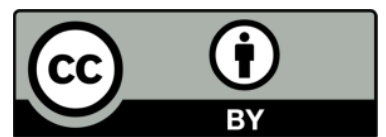

TANRA retain the copyright of published articles, which is released under a "Creative Commons Attribution License for CC-BY-4.0" enabling the unrestricted use, distribution, and reproduction of an article in any medium, provided that the original work is properly cited.

Citation: Anmar Mare Hassan $\mathrm{Al}$ Juboury Dr. Moyassar I. Ahmed Al juboury(2021). Designing an ERP System by Adopting the Decision Tree Algorithm: A Case Study in the General Company of Oil Products Distribution. TANMIYAT ALRAFIDAIN, 40 (130), 102 -134, https://doi.org/

10.33899/tanra.2021.168687

P-ISSN: 1609-591X e-ISSN: 2664-276X tanmiyat.mosuljournals.com

\author{
Anmar Mare Hassan Al Juboury ${ }^{1}$; Dr. Moyassar I. Ahmed Al juboury \\ ${ }^{1 \& r}$ University of Mosul
}

Corresponding author: Presidency University of Mosul.University of Mosul, anmar.aljuboury@gmail.com

DOI: https://doi.org/ 10.33899/tanra.2021.168687

Article History: Received: 9/2/2020; Revised: 10/9/2020; Accepted: 16/9/2020; Published: 1/6/2021.

\begin{abstract}
Abstract The study endeavored to design a proposed system model of ERP by adopting an algorithm. The study was applied in the Oil Products Distribution Company -Iraq. The problem of the study was manifested by many questions regarding the level of the viewpoints on the system of ERP and the support presented by the possible managers and users in the company, and the most influential motivations in adopting the system and the good features attained from using it. The case study system was adopted by making use of many sighting and on-field interviews, and depending on documents and records in gathering data and the necessary information, in addition to the checklist which included 35 responders from different levels of the company management officials. The analysis was carried out depending on the suitable statistical tools through using the statistical program of (pass) to know the motivations behind adopting the system of ERP and the results expected from using it. Designing the ERP system was the essential objective of the study and it was accomplished by (My SQL Database version 5.717 ), the structural information language SQL, the software program language OHP 5.6 30, the language of designing the site profile HTML, and the coordination language CSS 4 . The study has come up with a group of conclusions, some of them were linked to the analysis results of the preliminary realization of the motivations behind adopting the system of ERP and the good features attained from designing and operating it to managers and it is within the accepted level and on the positive direction, due to the absence of a unified central database that provides information to different parts of the company, information that can be used making decisions because gathering data is done a single basis. This paved the way to present a proposed model for the system with the existence of certain provisions among which the participation of all managers effectively in every step of applying the system of ERP, as well as the necessity of guiding specialized personals (analysts and programmers) so that they might supervise the managing of the system and activate its activation. The study recommended the information communication of its subject matters through several titles for future studies.
\end{abstract}

Keywords

ERP system, drivers for adopting ERP system, ERP system operation results, $\mathbf{C 5 . 0}$ decision tree algorithm 


\section{ورقة بحثية \\ ERP تصميم نموذج نظام مقترح لتخطيط موارد المشروع باعتماد خوارزمية وطبقت في شركة توزيع المنتجات التفطية مونة}

\author{
أنمار مرعي حسن الجبوري '؛ ميسر إبراهيم الجبوري \\ ا \& جامعة الموصل، كلية الإدارة والاقتصاد، قسم إدارة صناعية
}

المؤلف المراسل: أنمار مرعي حسن الجبوري، جامعة الموصل كلية الإدارة والاقتصاد، قسم إدارة صناعية ، anmar.aljuboury@gmail.com

DOI: https://doi.org/ 10.33899/tanra.2021.168687

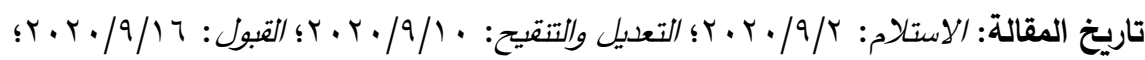

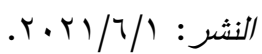

|لمستخلص

يهذف البحث إلى تحديد الإستراتيجية الخضراء وتثخيص مستوى تطبيقها في الدنظمة الدبحوثة وسعت

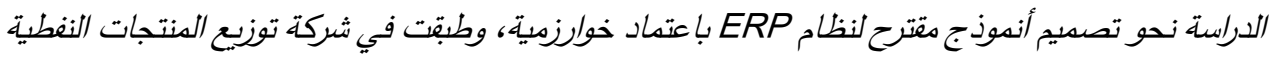

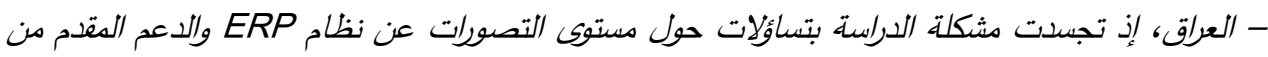

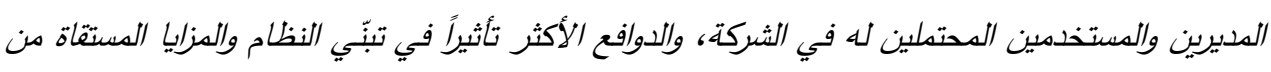

تشغيله.

تم اعتماد منهج دراسة الحالة باستخدام الهثاهدات والدقابلات الميدانية الدتعددة واعتماد الوثائق والسجلات

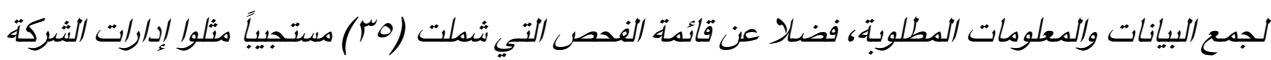

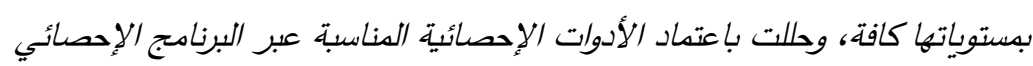
لغرض التعرف على دوافع تبني نظام ERP والنتائج المتوقعة من تشغيله.

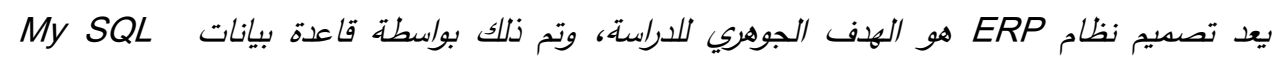

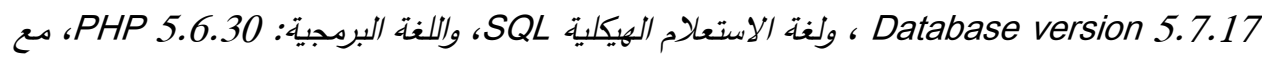

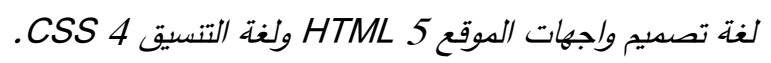

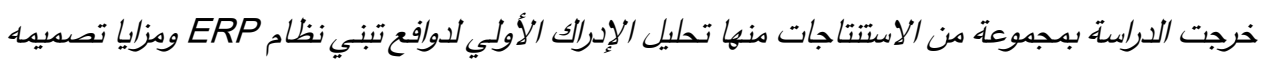

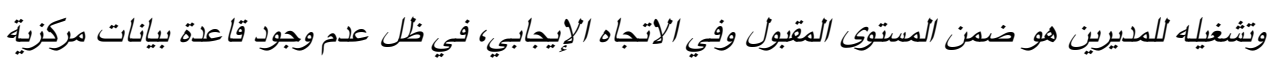

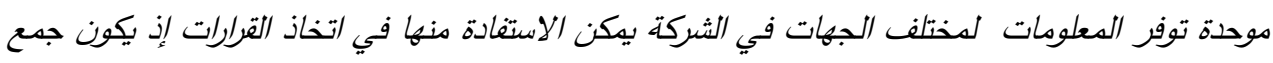

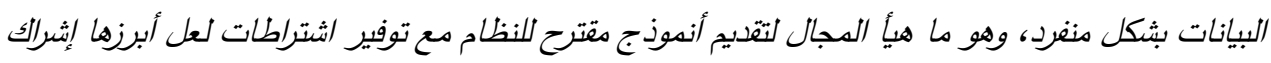

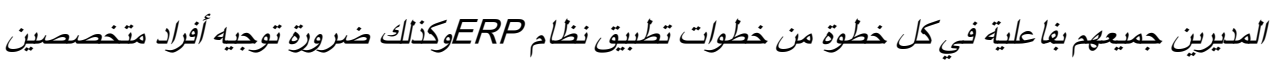
(محللين ومبرمجين ) تكون مهتهم الإثراف على إدارة النظام وتفعيل آليات تثغيله.

الكلمات المفتاحية نظام تخطيط موارد الثركة ERP ، دوافع تبني نظام ERP، نتائج تشغيل نظام ERP ، خوارزمية

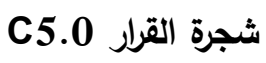

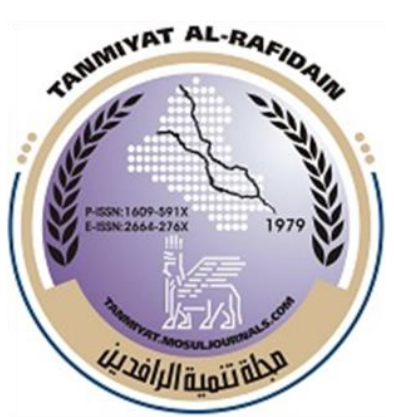

هبلة

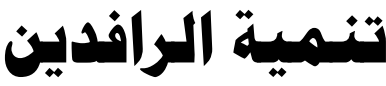

(TANRA) دولية، مفتوحة الوصول، محكمة.

$$
\begin{aligned}
& \text { المجلد (•• )، العدد (•r (1)، } \\
& \text { حزيران I.r.r }
\end{aligned}
$$

ج جامعة الموصل | كلية الإدارة والاقتصاد، الدوصل، العراق.

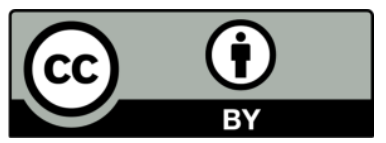

تحتفظ (TANRA) بحقوق الطبع والنشر للمقالات

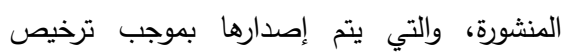
」 (Creative Commons Attribution) (CC-BY-4.0)

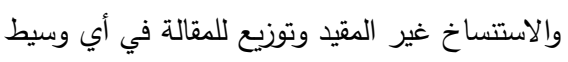
نقل، بشرط اقتباس العمل الأصلي بشكل صحيح. الاقتباس: الجبوري، أنمار مرعي حسن،

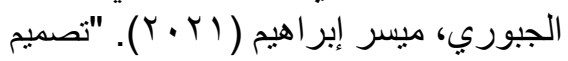

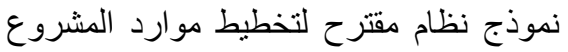

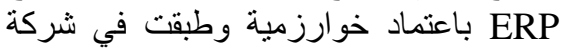

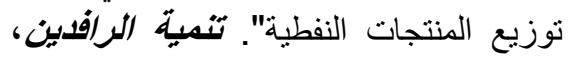

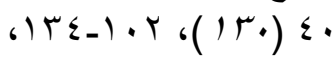

https://doi.org/

10.33899/tanra.2021.168687

P-ISSN: 1609-591X

e-ISSN: 2664-276X

tanmiyat.mosuljournals.com 
استجابة لإفرازات التحول الرقمي والتطور المضطرد في تقانات المعلومات بدأت أغلب الثركات بالتحول نحو العمل الالكتروني تدريجياً خصوصا تلك التي تؤهلها بنيتها التحتية لذلك، وفي الوقت ذاته تثجع العديد من الباحثين على محاولة تطبيقات تحل محل النظم التقليدية، وتكون قادرة على التعامل

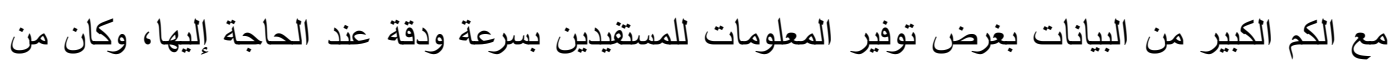

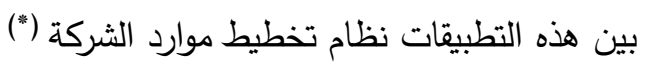
(Enterprise Resource Planning (ERP)

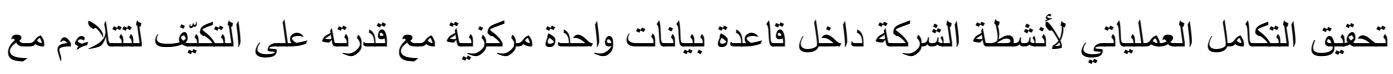
احتياجاتها المتعددة والمتتوعة. تسعى الدراسة لبناء نظام الكتروني مقترح لـ ERP بالتطبيق في الشركة العامة لتوزيع المنتجات

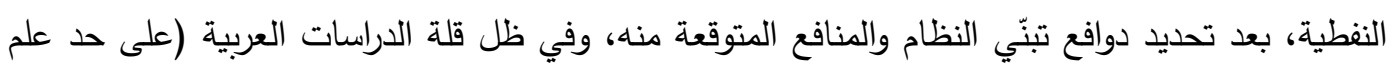
الباحث) التي تناولت المجال التطبيقي المستهدف، عدت الدراسة الحاضرة محاولة لتتاول الموضوع من جانبين أساسيين تتاول الأول المرتكزات الفكرية للنظام وتناول الثاني تصميم نظام الكتروني مقترح لـ ERP باعتماد

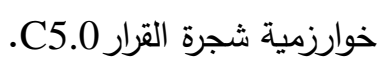

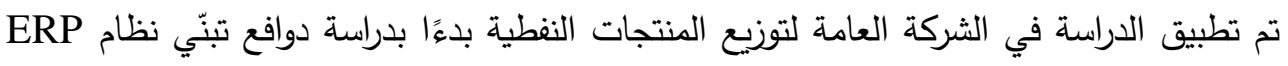

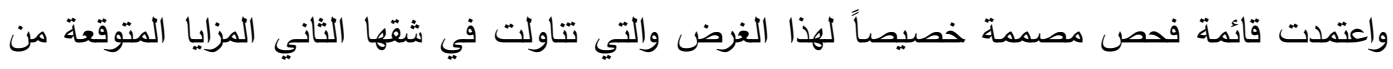
التطبيق طبقاً لمستخدمي النظام. تضمنت الدراسة الحالية مقدمة وأربعة محاور وعلى النحو الآتي :

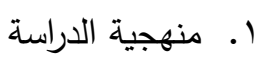

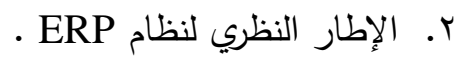

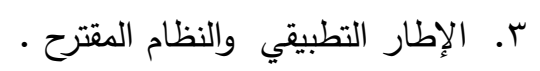
ع. الاستنتاجات والمقترحات والتوصيات

\section{أولاً : منهجية الاراسة}

1 - معضلة الدراسة الفكرية وإلمثكلة الأساسية الاسية

تبحث الشركات عامة وشركات توزيع المنتجات النفطية خاصة عن تقنيات وتطبيقات تحقق التكامل

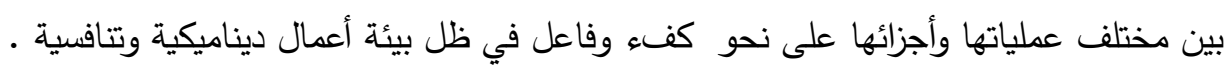

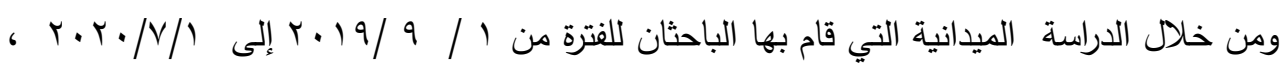

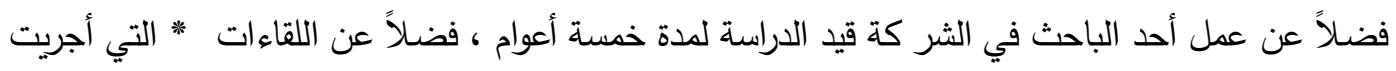


مع المديرين في مقر وزارة النفط - مركز البحث والتطوير النفطي أو في مقر الثركة، تأثّر مواجهة إدارة

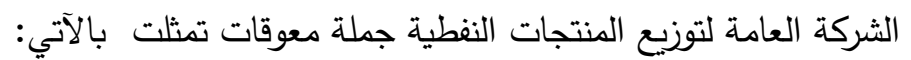
• • الاعتماد على النظم التقليدية في عملية توزيع المنتجات النفطية.

• عدم وجود نظام معلومات متكامل في عمليات توزيع المنتجات النفطية. • عدم الاعتماد في توزيع منتوج (البنزين) على المحطات على أساس الكثافة السكانية، سبب تباينًا

$$
\text { في توزيع الحصص على محطات التعبئة . }
$$

• غياب نظام واحد متكامل لكافة عمليات الثركة.

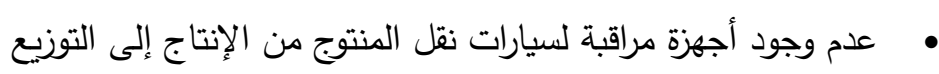

وعلى ضوء ذلك تم صياغة مشكلة الدراسة والتعبير عنها بالتساؤلات الآتية :

ا. ما مستوى الإدراك والتصورات عن ERP لدى المديرين والمستخدمين المحتملين له في الثركة العامة

$$
\text { لتوزيع المنتجات النفطية ؟ }
$$

r. هل تقدم الإدارة العليا في الثركة قيد الدراسة الدعم اللازم وتصوغ الإستراتيجية الفعالة، وتوفر الموارد

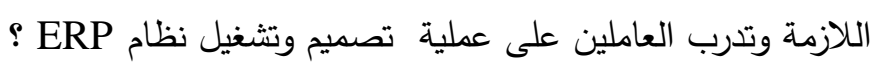

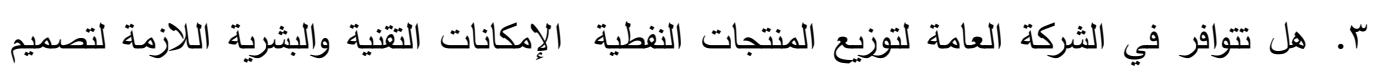

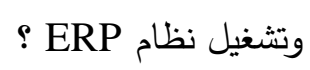

ع. ما الدوافع الأكثر تأثيراً في تبنّي نظام ERP في الثركة العامة لتوزيع المنتجات النفطية ؟ ه. يحقق تشغيل نظام ERP باعتماد شجرة القرار جملة من المزايا يتمكن المديرون والمستخدمون من فئن

التعاطي معها؟

$$
\text { r - r r أهمية الدراسة }
$$

يمكن تحديد أهمية الدراسة على وفق المستويين الأكاديمي والتطبيقي وكما يآتي:

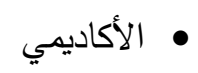

• السعي لتقديم إطار نظري واضح ومعاصر لنظام ERP يسهم بتواضع في إثراء المكتبة العراقية

$$
\text { والعربية. }
$$

• توفير التأصيل النظري والميداني لخطوات تطبيق نظام ERP على نحو متسلسل •

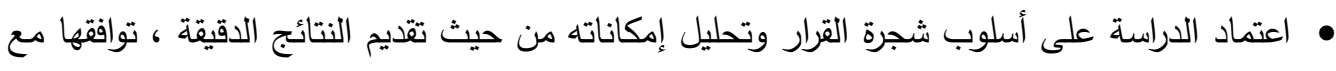
حالة تزايد عدد البيانات في التطبيقات المختلفة وصنع القرار بصورة سلسة، استخراج البيانات بيسر ،

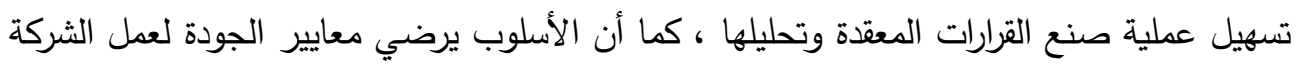

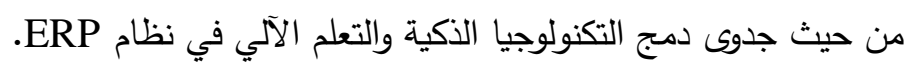
• التطبيقي 
• إظهار الدوافع الجوهرية التي تدفع إدارة الثركات التي تتبع وزارة النفط العراقية على التفكير بتطبيق نظام ERP ومغادرة النظم التقليدية لما يمكن أن يحققه من فوائد محتملة .

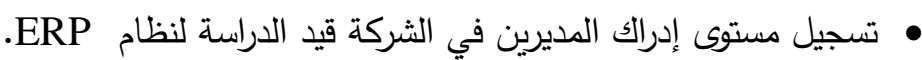
• المساعدة في تحقيق عدالة توزيع المنتجات النفطية بين المحطات.

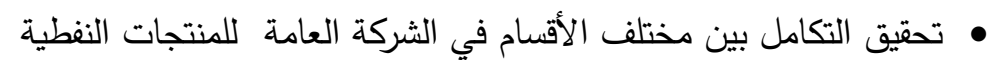
• تقديم معلومات أكثر استجابة لمتطلبات متخذ القرار، مع تحقيق سرعة الاستجابة لمتطلبات الزبائن

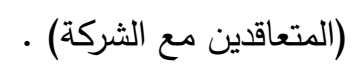

• الوصول إلى تكامل واقعي للعمليات في نظام موحد يهدف خفض الوقت اللازم لأدائها مع الأح

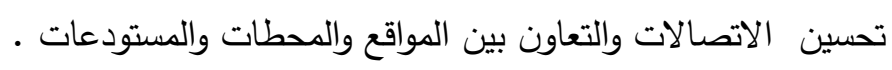

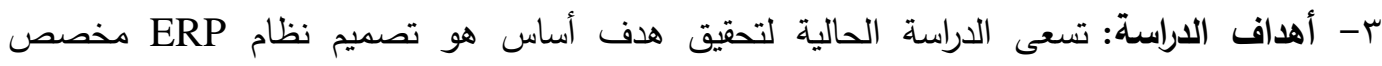

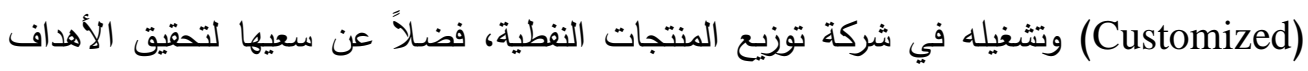

1. المساهمة في النهوض بواقع الثركة قيد الدراسة وجعلها مواكبة للممارسات المعاصرة من خلال

اقتراح نظام ERP وتثغيله في الشركات العراقية ومنها شركة توزيع المنتجات النفطية .

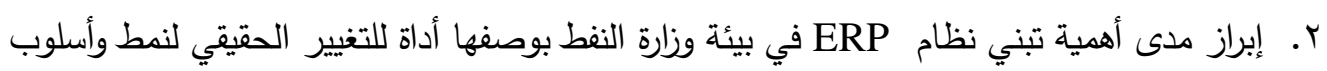
الإدارة بالاستعانة بأهم التقنيات المستخدمة ومدى الدور الذي يمكن أن تؤديه في توفير المعلومات

$$
\text { لمتخذ القرار. }
$$

r. توضيح خطوات تطبيق النظام من خلال مخطط الدراسة المقترح الذي يتضمن خطوات متسلسلة

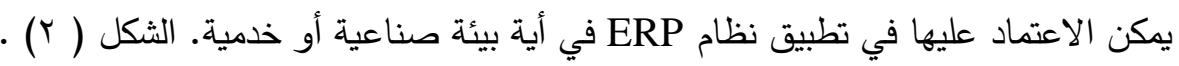
ع. الكثف عن مدى إسهام تطبيق النظام المقترح باعتماد شجرة القرار في تحسين مستوى الأداء الكلي

$$
\text { ع - مخطط الاراسة وفرضي الشركة قيد الدراسة . }
$$

يعرض الثكل (r) مخطط لخطوات الدراسة وتسلسلها المنهجي الذي امتد لسبع خطوات تبيّن انتقالات تسعى للتصدي لمظاهر مشكلة الدراسة، وتسهم في تحقيق أهدافها. ويظهر الثكل دوافع ERP وتصميمه وتثغيله والتأكد من استثمار ميزاته في واقع عمليات الثركة قيد الدراسة. 
تصميم نموذج نظام مقترح لتخطيط موارد المشروع .........

الجبوري والجبوري

الثكل 1: أنموذج وخطوات الاراسة

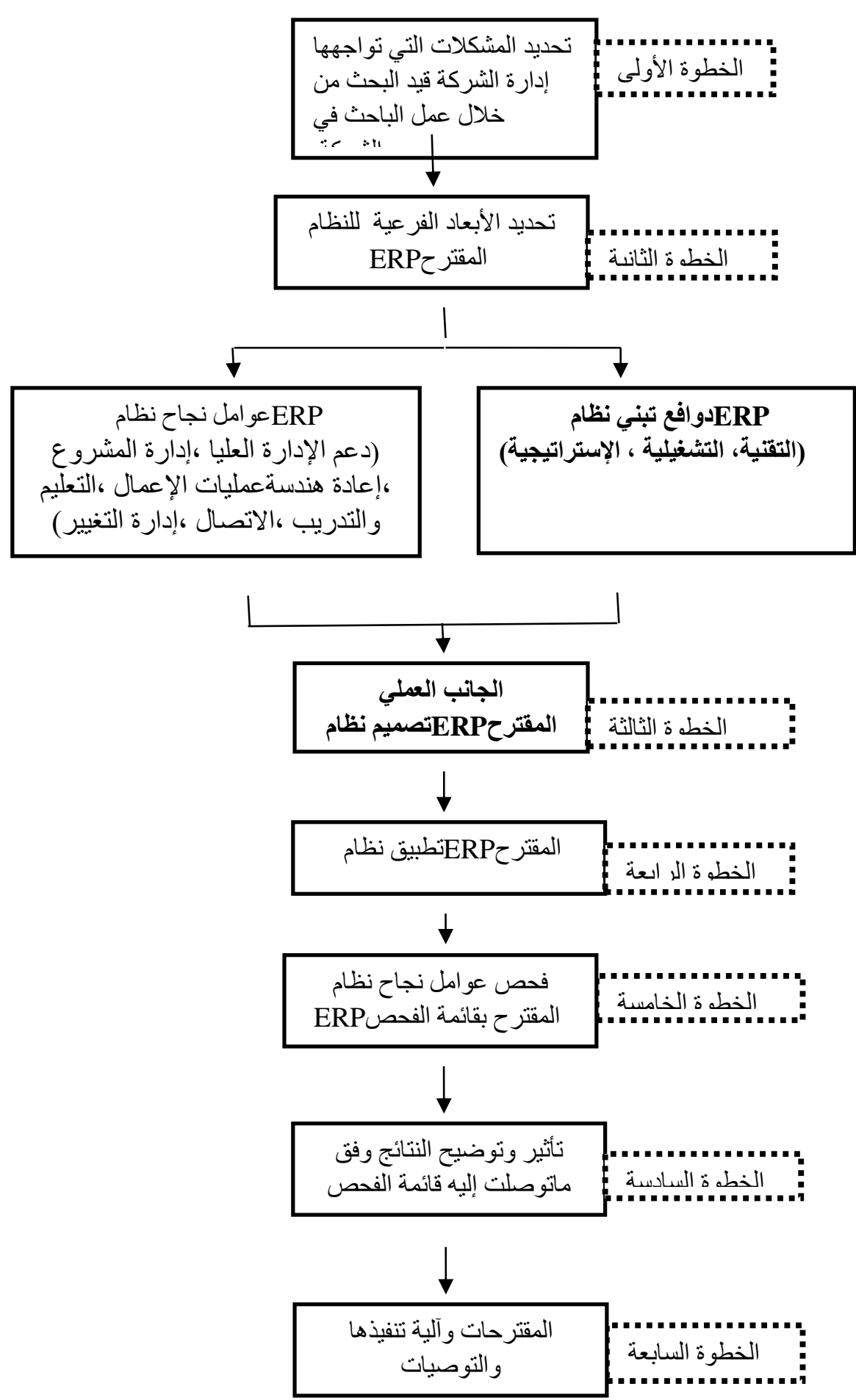

المصدر : من إعداد الباحثين •

TANMIYAT AL-RAFIDAIN (P-ISSN: 1609-591X; E-ISSN: 2664-276X) تنمية الرافدين 
واستتاداً إلى الثكل المذكور آنفآ ، وتوافقاً مع تساؤلات الدراسة وأهدافها تم صياغة الفرضيات الآتية:

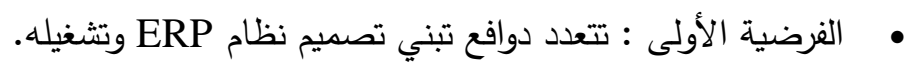
• الفرضية الثانية : تتباين دوافع التصميم والتثغيل وفق مستويات أهمية مختلفة. . • الفرضية الثالثة: يمكن تأشير مزايا تطبيق نظام ERP بوصفها واقعاً ملموساً للزبائن.

$$
\text { ه - منهج الدراسة : }
$$

اعتمد الباحث أسلوب دراسة الحالة للميزات العديدة التي يقدمها من حيث التحليل التقصيلي و

$$
\text { الموضوعية وتطبيق أكثر من أسلوب بحثي في آن واحد (الملاحظة والمقابلة). }
$$

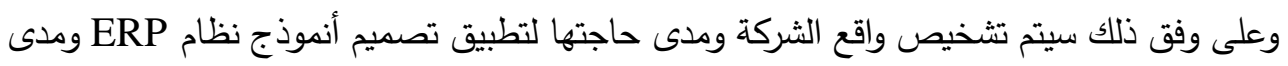

توفر دوافع تبنّي النظام ، وقد اعتمد الباحث الأسلوب الوصفي في عرض الأسس النظرية للدراسة من خلد

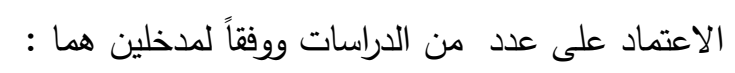

الدذخل الإداري: ويتمثل بالأدبيات التي عالجت مواضيع الدراسة يتقدمها ما يرتبط بتصميم أنموذج نظام

$$
\text { ERP }
$$

1. المدخل البرمجي: ويعتمد تصميم الأنموذج البرمجي ومعالجة البيانات والتركيز على قاعدة البيانات

$$
\text { التثغيلية ومستودع البيانات. }
$$

צ- حدود الاراسة

1. الحدود الزمانية :انحصرت الحدود الزمانية للدراسة في المدة من شهر كانون الأول 9 الـ ب إلى آب

r. الحدود المكانية: اقتصرت الدراسة على الثركة العامة لتوزيع المنتجات النفطية وهي تمتد من جنوب

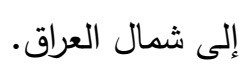

r. دود الأثخاص: استهدفت الدراسة عينة من المديرين ومستخدمي النظام الذين لهم علاقة بنظام ERP بواقع • r فرداً موزعين بين مقر الثركة وأقسامها و المحطات والمستودعات.

ثانياً : الإطار النظري لنظام ERP

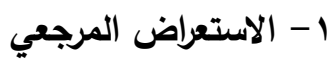

ركزت الدراسات على اختيار الثركات التي نفذت تصميم نظام ERP كما ركزت على دوافع تبني

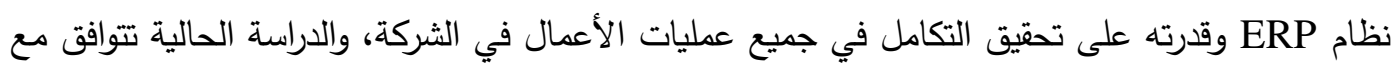
Jafari,2020)\& （Mishra \& Mishra,2011) (Menon الدراسات 
(Atukwase, 2016\&Scholtz) من حيث مجال التطبيق، ودراستي (AL Jafar\&Nair, 2019)

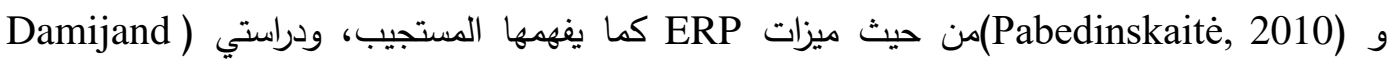
(Rajkovic,2015) و (Jenab and Staubb,2019) من حيث الأداة الساندة وهي شجرة القرار . في حين اعتمدت بعض الدراسات ومنها دراسة (Chen,2018,963) مخططًا يوضح خطوات البحث التي تمثل مراحل تبني نظام ERP وهو ما اعتمدته الدراسة الحالية .

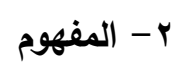

يعده (Alter,2002,576) نظاماً للمعلومات يستعمل قاعدة البيانات المتكاملة لتزويد البنية التحتية المتكاملة لعمليات الأعمال الأنموذجية ضمن المجالات الوظيفية والمعلومات عبر المجالات المختلفة وعملياً توزعت آراء الكتاب حول مفهوم نظام ERP حول منظورين الأول إداري والآخر برمجي وأدناه استعراض للمنظورين: ا ـ المنظور الإداري (العملية الإدارية): وفقاً لـ ـ (Mihails Savrasovs, 2019) هي نظام معلومات

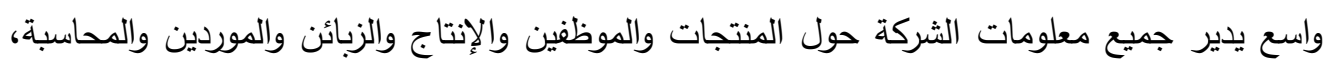

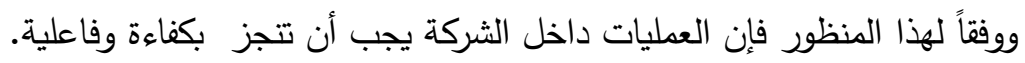

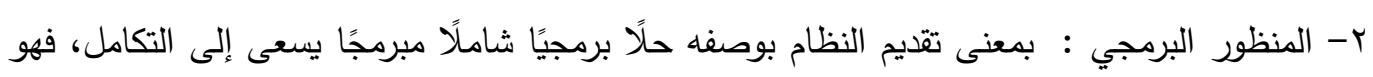

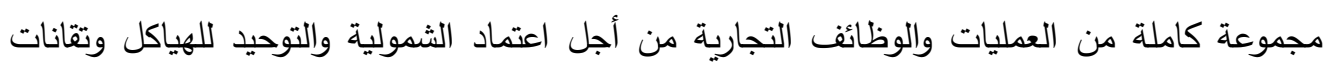

$$
\text { المعلومات. }
$$

ب- بار التطور التاريخي لنظام ERP:

تاريخياً يرى (Park Lee,2006,42) أن Gartner Group هي المجموعة التي ابتكرت تسمية ERP بوصفه مجموعة من التطبيقات التي تصمم لجلب وظائف الإعمال إلى الميزان، وهو يمثل الجيل القادم لأنظمة العمل.

ويبين (Bradford, M,2015,43) شكلاً (r) يلخص التطور التاريخي لنظامERP . 


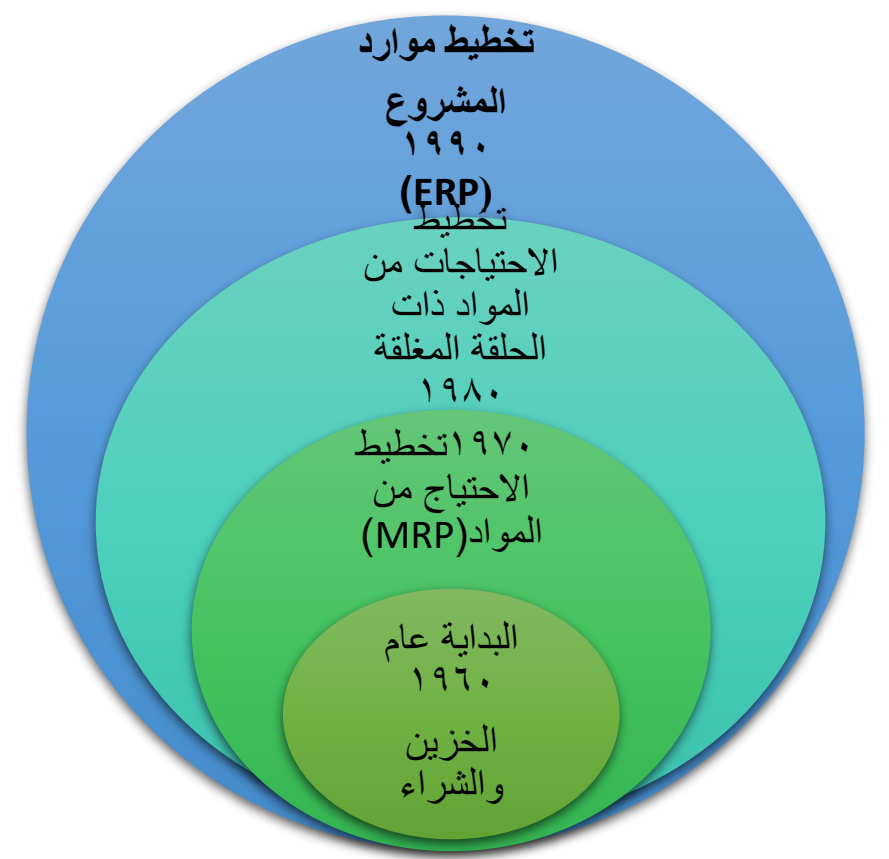

الثكل (ץ) يلخص التطور التاريخي لنظامERP

ع_ دوافع تبنّي نظام ERP و تصميمه وتثنغيله

تتاول الباحثون مجموعة من العوامل المتعددة والمتنوعة التي تسهم في الدفع باتجاه تطبيق ERP، لدئه وامتد ذلك ليشمل تسمية العوامل نفسها مع إقرارهم بالاتفاق حول تتاولها جميعاً تحت عنوان واحد هو (عامل)

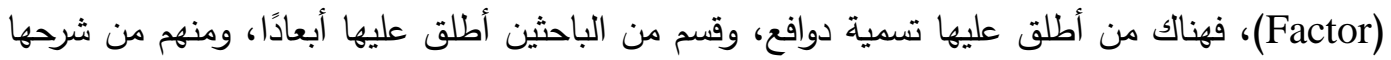
تحت عنوان أسباب تبنّي نظام ERP، وسيجري طرح هذه الآراء تباعاً. إذ أورد (Turner\&Weickgenannt,2009,609) هذه العوامل تحت عنوان العوامل المهمة Success ( تتاولها تحت عنوان عوامل النجاح (Important Factors) Critical Success (Factor Factor فهي تختلف من شركة إلى أخرى ومن منطقة إلى أخرى ومن وقت إلى إلى آخر .

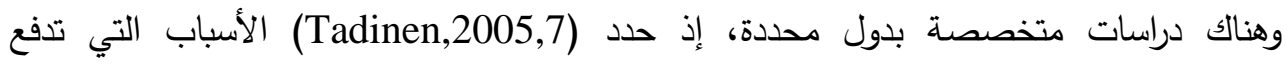
الشركات إلى تطبيق النظام في الولايات المتحدة الأمريكية والسويد وفق رتب رقمية معبر عنها بدرجات حيث درجة ( (غير مهم ) وصولاً إلى الدرجة ه (بالغ الأهمية) (الجدول (1). 
تصميم نموذج نظام مقترح لتخطيط موارد المشروع .

الجبوري والجبوري

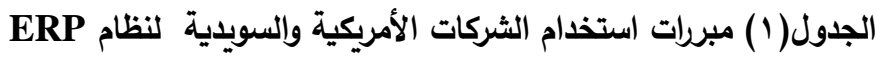

\begin{tabular}{|c|c|c|}
\hline 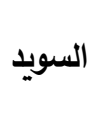 & الوالايات المتحدة & الأسباب \\
\hline$\varepsilon, 11$ & $\varepsilon, \cdot 7$ & استبدال النظم التقليدية . \\
\hline$r, T V$ & r, ^o & تبسيط وتوحيد الأنظمة . \\
\hline$r, 17$ & $r, \infty 0$ & أخرى. تحسين التفاعلات بين والمجهزين من جهة والزبائن من جهة \\
\hline$r, 1 \wedge$ & $r, \leqslant 7$ & الحصول على ميزة إستراتيجبة . \\
\hline r,AO & $r, I V$ & 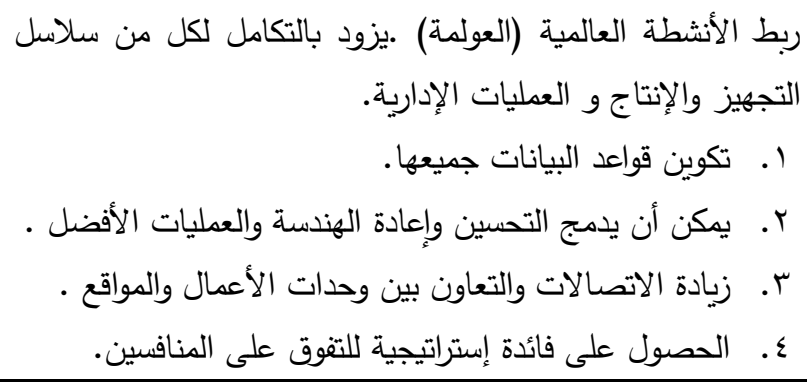 \\
\hline$r, \varepsilon \wedge$ & $r, 99$ & الضغط لمواكبة المنافسين . \\
\hline r,97 & $r, 9)$ & سهولة تطوير الأنظمة . \\
\hline$r, V \cdot$ & $r, 01$ & إعادة هيكلة الشركة . \\
\hline
\end{tabular}

وفي الأطار ذاته قدم (Burton,2011,132) شكلاً يوضح خمس كفاءات جوهرية إذا أرادت الثركة

تبني نظام ERP

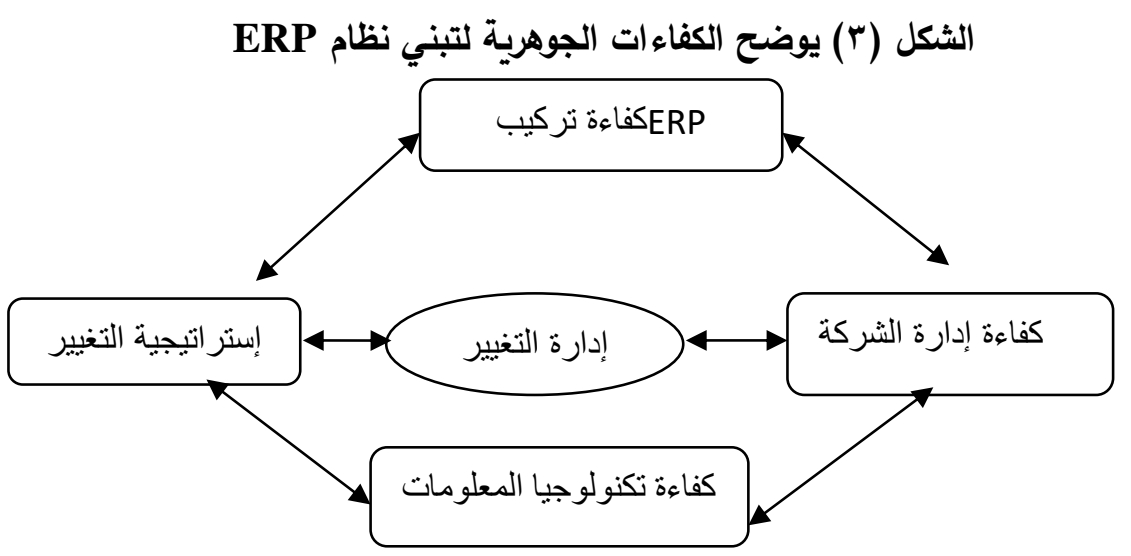

تمكن الباحث من الاطلاع على مجموعة من الباحثين اتفقوا على مجموعة من الدوافع لتطبيق نظام

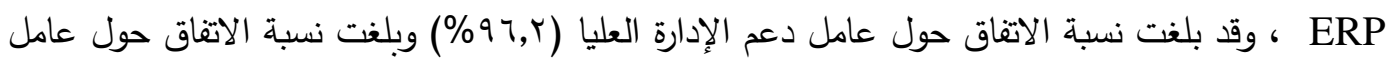

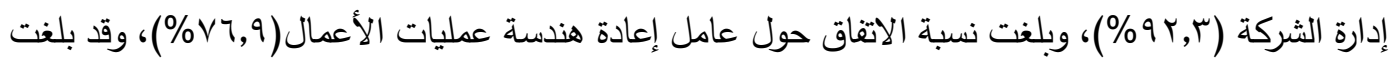

TANMIYAT AL-RAFIDAIN (P-ISSN: 1609-591X; E-ISSN: 2664-276X) تنمية الرافدين 


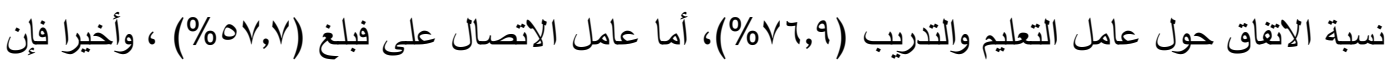

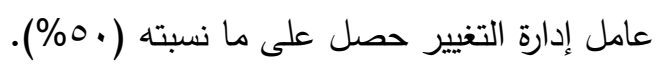

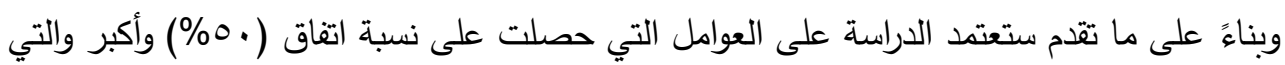

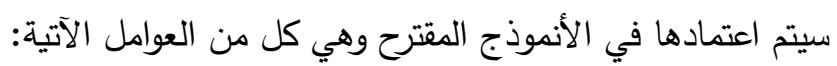

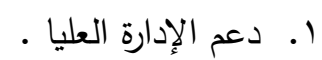

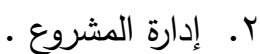

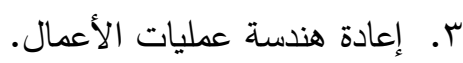

ع. التعليم والتدريب.

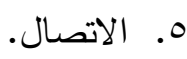

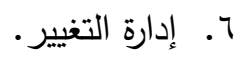

رابعاً: الاطار التطبيقي والنظام المقترح

1 - نبذة تعريفية مختصرة عن مجتمع البحث: نبذة تعريفية عن الشركة العامة لتوزيع المنتجات النفطية

$$
\text { وأنشطة توزيعها الجغرافي والمستفيدين من منتجاتها. }
$$

أ. عنوان التشريع: تأسيس شركة توزيع المنتجات النفطية - شركة عامة التصنيف: بيان التهات المحتوى

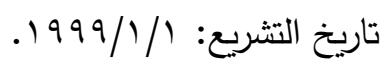

ب. اسم الشركة : شركة توزيع المنتجات النفطية (( شركة عامة )) • موقعها ومركزها الرئيس: الدورة -

بغداد ، فتح لها فروع و مكاتب أخرى داخل البلد في كافة المحافظات ومنح وقبول الوكالات. ت. أهداف الثركة : تهدف الشركة إلى المساهمة في دعم الاقتصاد الوطني في مجال القطاع النفطي من خلال توزيع وبيع المنتجات النفطية بما يحقق أهداف خطط التتمية والخطط المعتمدة في وزارة

ث. نشاط الثركة : تمارس الشركة لغرض تحقيق أهدافها الأنشطة الآتية وفق أحكام قانون تتظيم وزارة

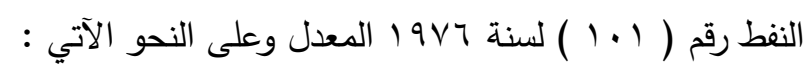

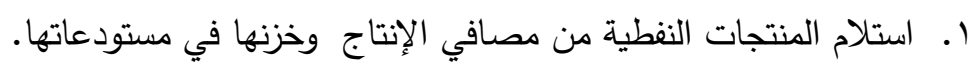

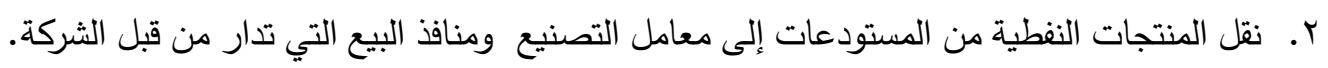

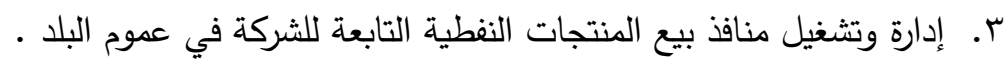

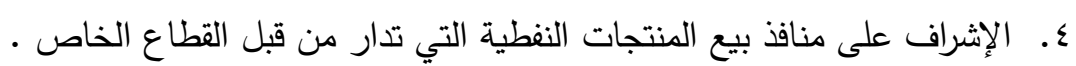

ه. بيع المنتجات النفطية إلى المواطنين والمؤسسات القطاعية .

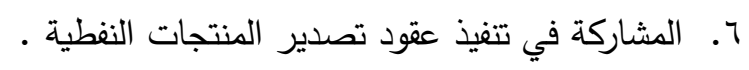

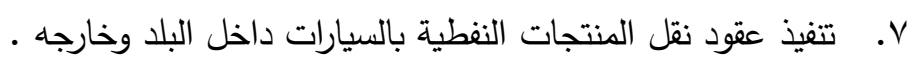

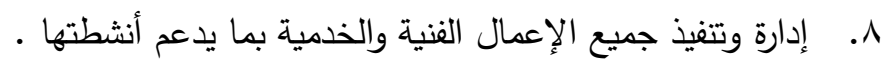


r - عرض نتائج قائمة الفحص وتحليلها : تم تحليل البيانات التي تم جمعها عن كل من دوافع تبني نظام

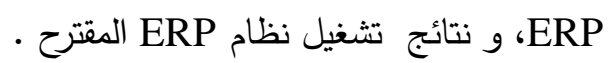
أ- دوافع تبني نظام ERP: إن نظام تخطيط موارد الشركة (ERP) يمثل نظامًا قادرًا على تتظيم وتوحيد

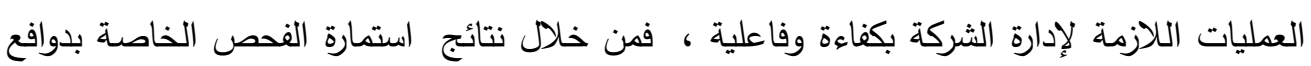

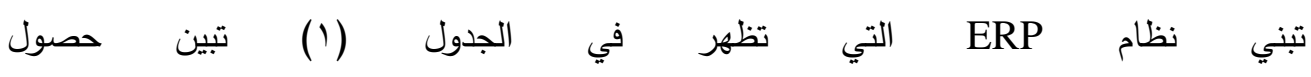

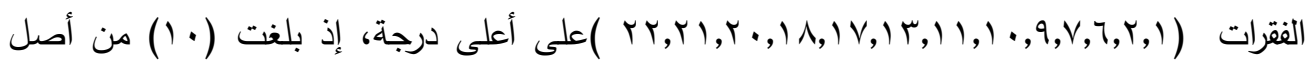

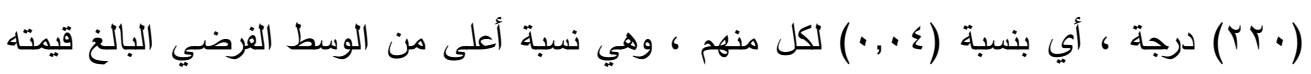

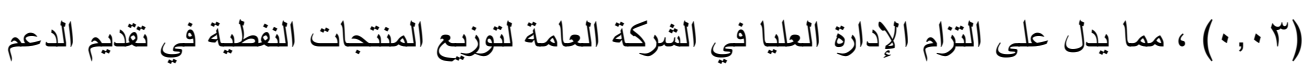

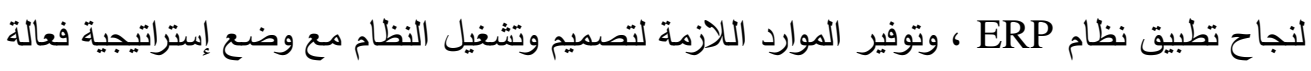

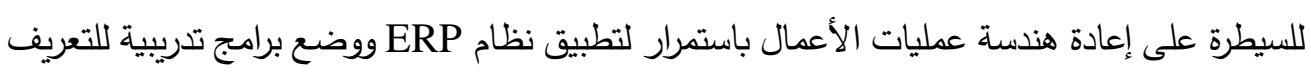

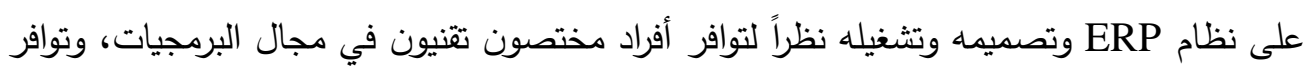

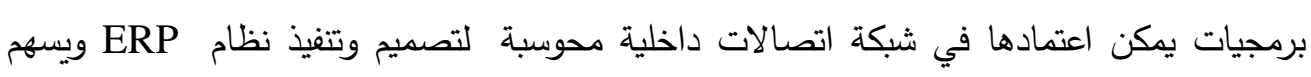
التصديم الكفه للنظام المقترح ERP في تقديم معلومات أكثر استجابة لمتطلبات متخذ القرار وتحقيق

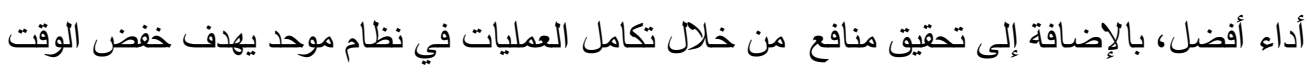
اللازم لأداء العمليات المختلفة في كافة مواقع الثركة العامة لتعاف لتوزيع المنتجات النفطية ، أما بالنسبة

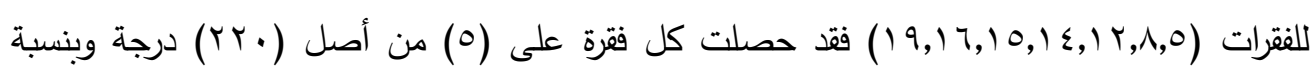

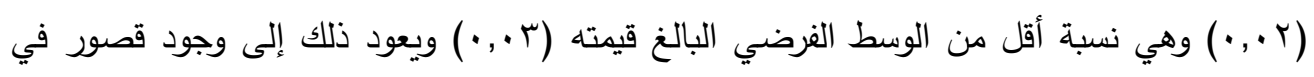
تصور أركان نظام ERP وأدوات تثغيله والسعي إلى حل مشكلات في تتفيذ عملية إعادة هندسة العمليات لتطبيق نظام ERP من خلال المختصين في البرمجيات في الشركة أو الاستعانة باستشاريين من خارج الشركة لتدريب فرق العمل على تطبيق نظام تخطيط ERP بشكل سليم في لإيصال أهداف

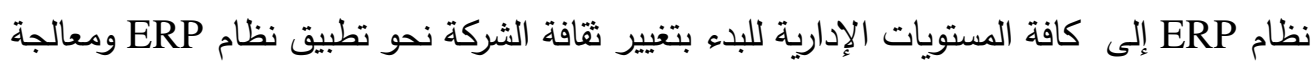

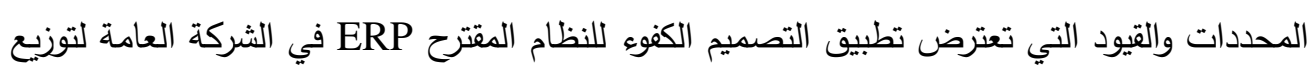

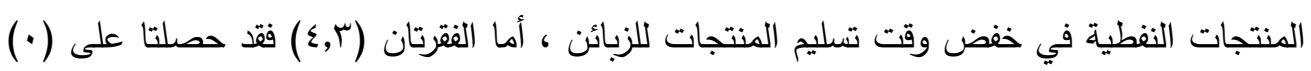

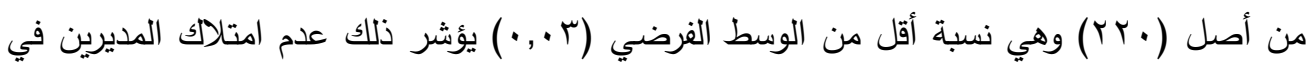
الثركة العامة لتوزيع المنتجات النفطية مستوى إدراك مناسب عن نظام ERP للمشاركة جميعهم في

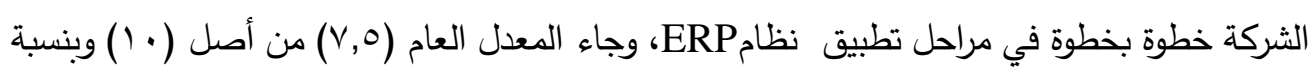

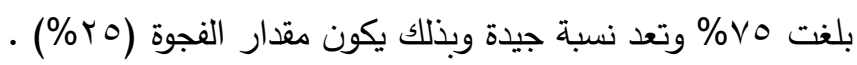

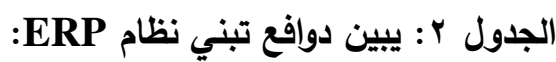

\begin{tabular}{|c|c|c|c|c|}
\hline ضعيف & متوسط & 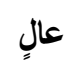 & 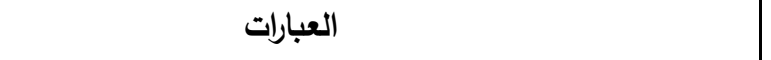 & $ت$ \\
\hline & & $\checkmark$ & تقدم الإدارة العليا في شركتنا الدعم لنجاح تطبيق نظام ERP & 1 \\
\hline
\end{tabular}


تصميم نموذج نظام مقترح لتخطيط موارد المشروع .........

الجبوري والجبوري

\begin{tabular}{|c|c|c|c|c|}
\hline ضعيف & متوسط & عالٍ & 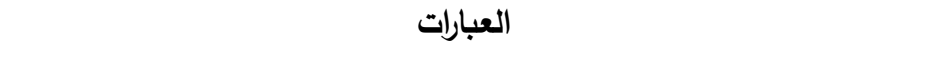 & $ت$ \\
\hline & & $\checkmark$ & توفر الإدارة العليا في شركتنا الموارد اتشغيله تصميم وتنفيذ نظام ERP. & r \\
\hline$\checkmark$ & & & يشارك المديرون جميعهم في شركتنا خطوة بخطوة في مراحل تطبيق نظام & $r$ \\
\hline \multirow[t]{4}{*}{$\checkmark$} & & & يمتلك المديرون المعنيون في شركتنا مستوى إدراك مناسب عن نظام ERP & $\varepsilon$ \\
\hline & $\checkmark$ & & يوجد تصور كافٍ عن أركان نظام ERP وأدوات تشغيله . & 0 \\
\hline & & $\checkmark$ & تتبنى شركتا وضع إستراتيجية فعالة للسيطرة على عمليات تطبيق نظام ERP. & 1 \\
\hline & & $\checkmark$ & 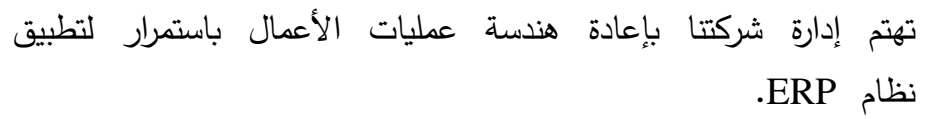 & v \\
\hline & $\checkmark$ & & 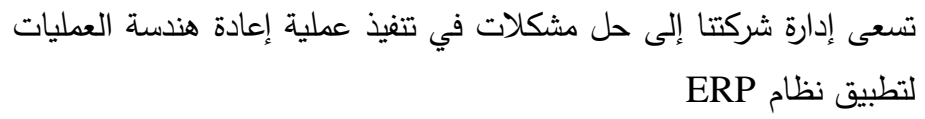 & $\wedge$ \\
\hline & & $\checkmark$ & تتظم إدارة شركتنا برامج تدريبية عن مواضيع مثل التعريف بنظام ERP & 9 \\
\hline & & $\checkmark$ & تتوافر لاى شركتنا برمجيات يمكن اعتمادها لتصميم وتتفيذ نظام ERP. & 1 . \\
\hline & & $\checkmark$ & 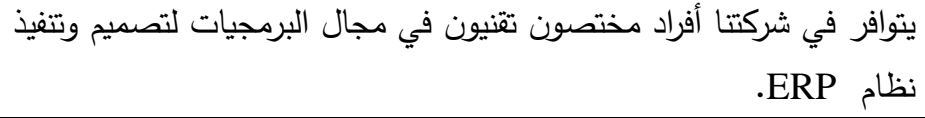 & 11 \\
\hline & $\checkmark$ & & 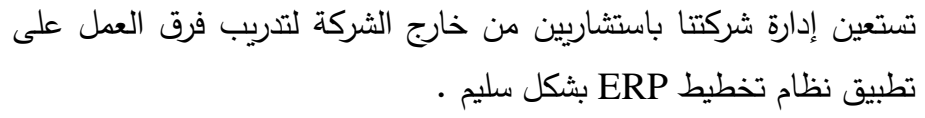 & Ir \\
\hline & & $\checkmark$ & تملك شركتنا شبكة اتصالات داخلية محوسبة لتطبيق نظام ERP. & 14 \\
\hline & $\checkmark$ & & تهتم شركتنا بالاتصالات الفعالة لإيصال أهداف نظام ERP إلى كافة & $1 \varepsilon$ \\
\hline & $\checkmark$ & & 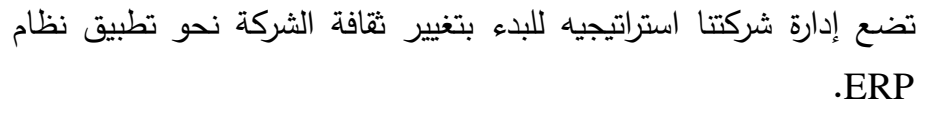 & 10 \\
\hline & $\checkmark$ & & تسعى شركتنا لمعالجة المحددات والقيود التي تعترض تطبيق نظام ERP & 17 \\
\hline & & $\checkmark$ & يتحقق أداء أفضل لشركتتا عند تصميم نظام ERP المقترح على نحو صحيح & IV \\
\hline & & $\checkmark$ & 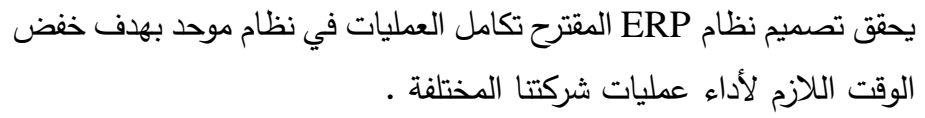 & 11 \\
\hline & $\checkmark$ & & يسهم التصميم الكفء للنظام المقترح ERP في شركتنا في خفض وقت تسليم & 19 \\
\hline
\end{tabular}

TANMIYAT AL-RAFIDAIN (P-ISSN: 1609-591X; E-ISSN: 2664-276X) تنمية الرافدين 


\begin{tabular}{|c|c|c|c|c|}
\hline 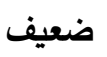 & 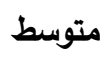 & 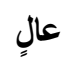 & العبارات & ت \\
\hline & & $\checkmark$ & 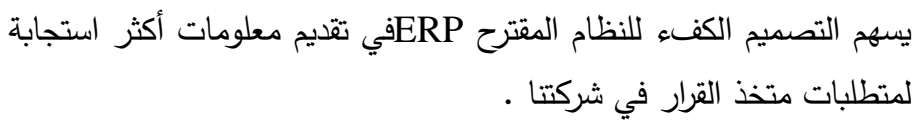 & $r$. \\
\hline & & $\checkmark$ & 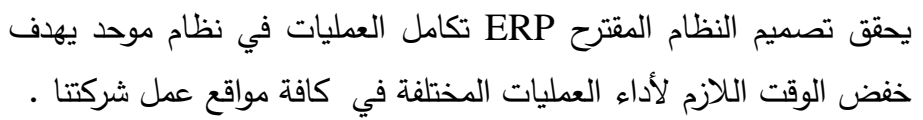 & rI \\
\hline & & $\checkmark$ & تتحقق منافع من تطبيق نظام ERP في شركتتا & r \\
\hline · & 0 & 1 . & 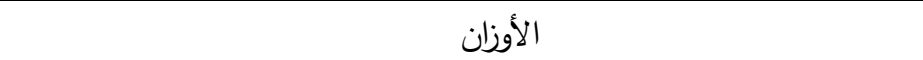 & \\
\hline r & V & r & التكرارات & \\
\hline . & ro & r. & النتيجة & \\
\hline \multicolumn{3}{|c|}{$\vee, 0$} & \multicolumn{2}{|l|}{ 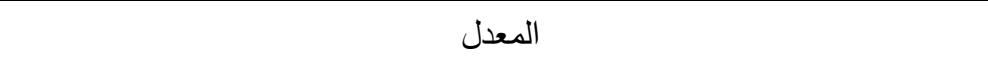 } \\
\hline \multicolumn{3}{|c|}{$\% \vee 0$} & \multicolumn{2}{|l|}{ النسبة المئوية للمطابقة } \\
\hline \multicolumn{3}{|c|}{$\cdot, \cdot r$} & \multicolumn{2}{|l|}{ مقدار الوسط الفرضي } \\
\hline \multicolumn{3}{|c|}{ ro } & \multicolumn{2}{|l|}{ مقدار الفجوة } \\
\hline
\end{tabular}

المصدر : من إعداد الباحثين اعتمادا على نتائج قائمة الفحص

ب- نتائج تشغيل نظام ERP : والتي تمثل تضمين برامج وتكنولوجيا متعددة في حزمة واحدة يمكن

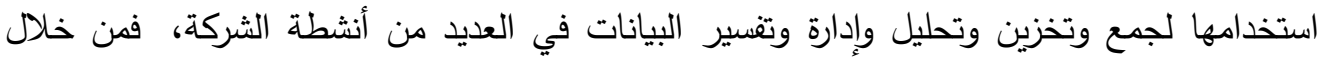
نتائج استمارة الفحص الخاصة بنتائج تشغيل نظام ERP التي تظهر في الجدول (Y) تبين حصول

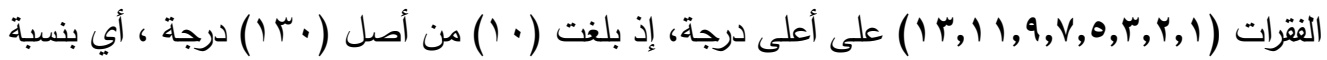

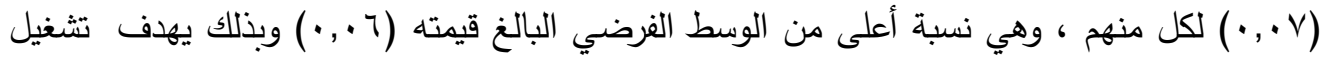

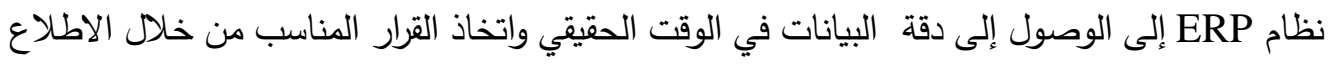
على كافة العمليات، ويحقق أداء أفضل في تقليل الإجراءات الإدارية المطلوبة من العاملين ويساعد إعادي تشغيل نظام ERP على زيادة الاتصالات والتعاون بين وحدات الأعمال في المواقع المختلفة، ويسهخ في خفض التكاليف وسرعة الاستجابة لمتطلبات الزبائن في الثركة العامة لتوزيع المنتجات النفطية ،

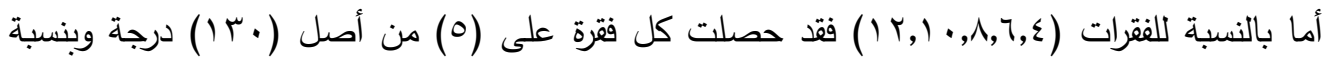

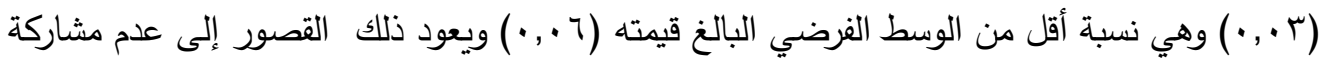

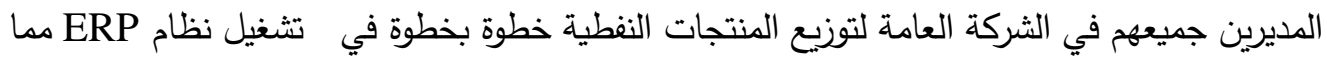
يساعد في خفض الوقت اللازم لانجاز عمليات الشركة المختلفة وتوحيد الهيكل التظظيمي للمواقع

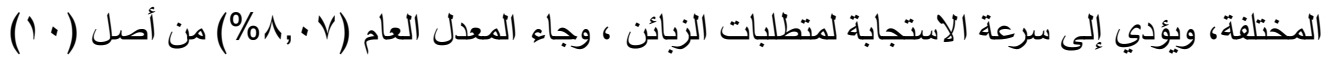
وبنسبة بلغت . ^\% وهي تعد نسبة . 
الجدول r: نتائج تشغيل نظام ERP المقترح في الثركة المبحوثة

\begin{tabular}{|c|c|c|c|c|}
\hline ضعيف & | متوسط & 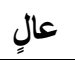 & 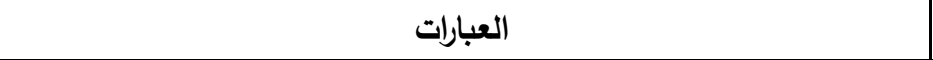 & $\Xi$ \\
\hline & & $\checkmark$ & كافة العمليات. تشغيل نظام ERP إلى اتخاذ القرار المناسب من خلال الإطلاع على & .1 \\
\hline & & $\checkmark$ & يهدف تشغيل نظام ERP إلى الوصول إلى البيانات في الوقت الحقيقي. & .1 \\
\hline & & $\checkmark$ & | يساعد تشغيل نظام ERP إلى الوصول إلى دقة البيانات. &.$r$ \\
\hline & $\checkmark$ & & يشارك المديرون جميعهم في شركتنا خطوة بخطوة في تشغيل نظام ERP. &.$\varepsilon$ \\
\hline & & $\checkmark$ & | يحقق تثغيل النظام المقترح ERP أداء أفضل لثركتنا . & .0 \\
\hline & $\checkmark$ & & يساعد تشغيل النظام المقترح ERP في خفض الوقت اللازم لانجاز عمليات & .7 \\
\hline & & $\checkmark$ & لمتطلبات الزبائن . تثغيل النظام المقترح ERP في خفض التكاليف وسرعة الاستجابة &.$V$ \\
\hline & $\checkmark$ & & يهدف تشغيل نظام المقترح ERP سرعة الاستجابة لدتطلبات الزبائن . & .1 \\
\hline & & $\checkmark$ & 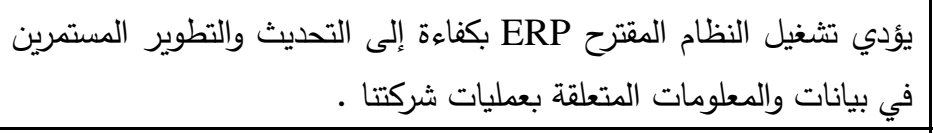 & .9 \\
\hline & $\checkmark$ & & 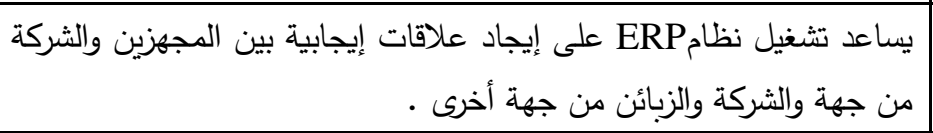 & .1. \\
\hline & & $\checkmark$ & 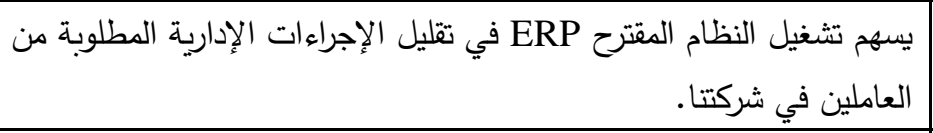 & .11 \\
\hline & $\checkmark$ & & 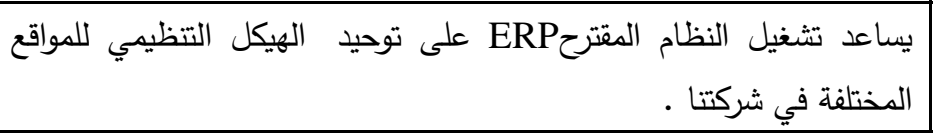 & .14 \\
\hline & & $\checkmark$ & 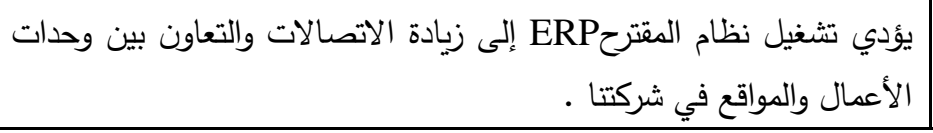 & .14 \\
\hline$\cdot$ & $\circ$ & 1. & & الأوز \\
\hline$\cdot$ & 。 & $\wedge$ & رات & التكرا \\
\hline · & ro & $\Lambda$. & & النتيح \\
\hline \multicolumn{3}{|c|}{$\% \wedge, \cdot \vee$} & & المعد \\
\hline \multicolumn{3}{|c|}{$\% \wedge$} & \multicolumn{2}{|c|}{ النسبة المئوية للمطابقة } \\
\hline \multicolumn{3}{|c|}{$\cdot, \cdot 7$} & \multicolumn{2}{|c|}{ مقدار الوسط الفرضي } \\
\hline & \multicolumn{2}{|c|}{ مقدار الفجوة } \\
\hline
\end{tabular}

TANMIYAT AL-RAFIDAIN (P-ISSN: 1609-591X; E-ISSN: 2664-276X) تنمية الرافدين 
ت- عرض إجمالي نتائج قائمة الفحص الخاصة بـ دوافع تبني نظام ERP ونتائج تشغيل نظام ERP لغرض الوقوف على مستوى توافر أبعاد دوافع تبني وتثغيل نظام ERP في الثركة العامة لتوزيع ليطي المنتجات النفطية ، وتحديد الواقع الفعلي لها ، يلخص الجدول (ع) نتائج قائمة الفحص الخاصة بـ دوافع تبني

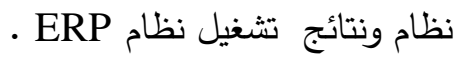

\begin{tabular}{|c|c|c|c|}
\hline \multicolumn{2}{|c|}{ نتائج تشغيل نظام ERP } & \multicolumn{2}{|c|}{ دوافع تبني نظام ERP } \\
\hline مقدار الفجوة & نسبة المطابقة & مقدار الفجوة & نسبة المطابقة \\
\hline$r$. & $\% \wedge$. & ro & $\%$ vo \\
\hline \multicolumn{3}{|c|}{$V V, O$} & المؤشر الكلي للمطابقة \\
\hline \multicolumn{3}{|c|}{ 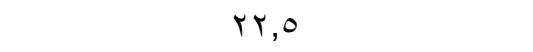 } & المؤشر الكلي للفجوة \\
\hline
\end{tabular}

المصدر من إعداد الباحثين استنادا إلى نتائج استمارة الفحص

من خلال الاطلاع على النتائج التي لخصها الجدول (ء) يمكن الخروج ببعض النقاط على النحو الآتي: ا. ـ سجل المؤشر الكلي للمطابقة لبعدي دوافع تبني نظام ERP ونتائج تثغيل نظام ERP بنسبة مقدارها

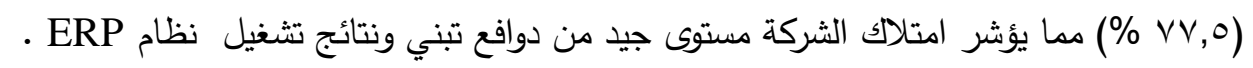

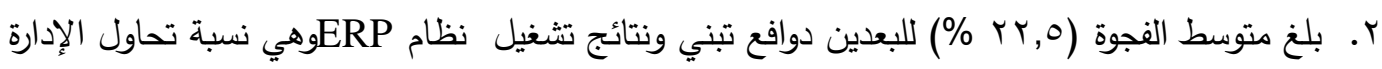

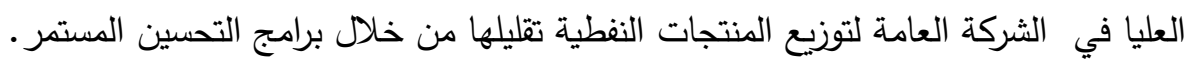
ث- خوارزمية شجرة القرار C5.0: هي إحدى أهم خوارزميات شجرة القرار يمكن أن تعتمد على صفة واحدة في بناء الثجرة، والصفة هنا (عمود Count of All)، وهذه مراحل عمل الخوارزمية: يستخدمC5.0 مفهوم الانتروبي En لقياس النقاء. يشير En في عي عينة البيانات إلى مدى اختلاط قيم

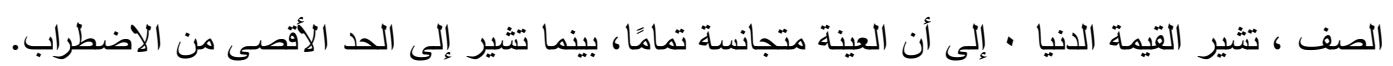

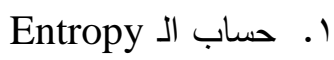
: إذ إن احتمالية حدوث كل صف Pi Log

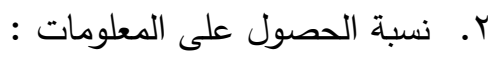


$\operatorname{Gain}(\mathrm{s}, \mathrm{v})=E(s)-\sum_{v} \frac{|S i|}{|S|} * E(S v)$

المعادلة هنا تضم خاصية واحدة ولذلك سيكون حسابها بسيطًا جداً ، إذ إن :

الـ S مقصود بها كل الصفوف للعمود الواحد

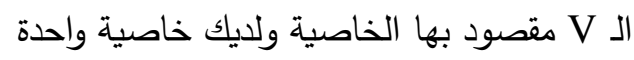

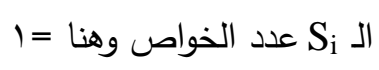

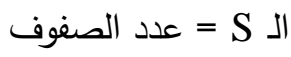

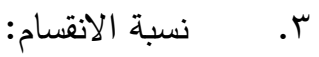

SplitInfo(s,v) $=\sum_{i=1}^{m}-\frac{|S i|}{|S|} * \log 2 \frac{|S i|}{|S|}$

$\operatorname{GainRatio}(\mathrm{s}, \mathrm{v})=\frac{\operatorname{Gain}(s, v)}{\operatorname{SplitInfo}(s, v)}$

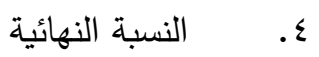

r- النظــام المقترح:

أ- وصف خوارزمية شجرة القرار C5.0 المعتمدة في تطبيق نظام ERP (المفهوم، الأهمية، الأهداف،

والمزايا)

المقدمة

تمثل الخوارزمية بكونها إجراء حسابيًا محددًا جيداً تعتمد على عدد من القيم باعتبارها مدخلات

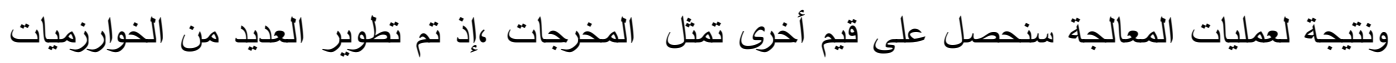

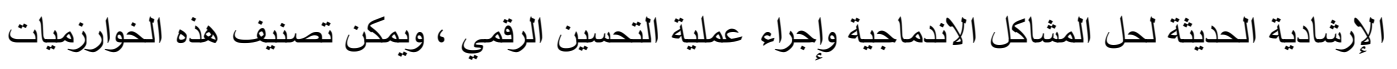

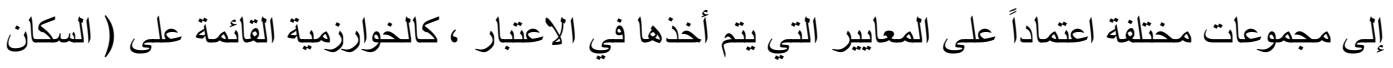

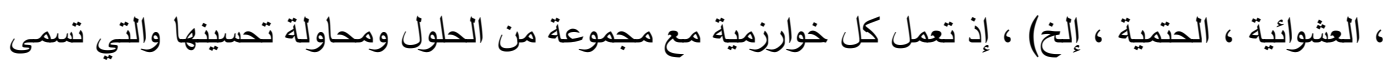

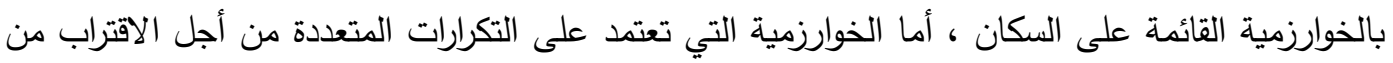

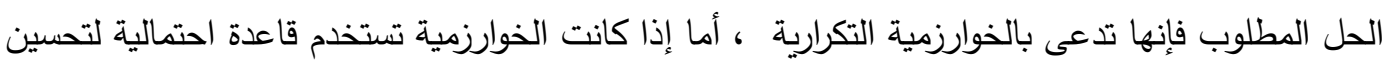
الحل عند ذلك فإنها تدعى بالخوارزمية الاحتمالية أو العشوائية .

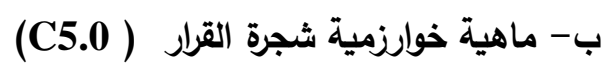

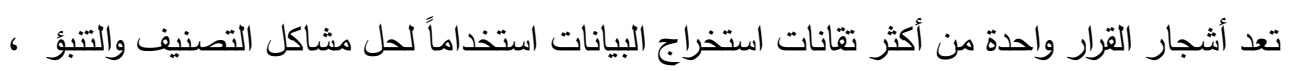

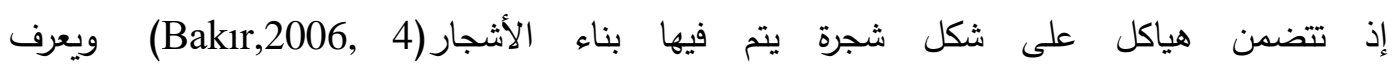
خوارزمية شجرة القرار بأنها بنية تحتوي على عقدة جذر وفروع (Kumar, 2016,2094\& Sharma)) 
وعقد أوراق تثير كل عقدة داخلية إلى اختبار سمة ، ويشير كل فرع إلى نتيجة الاختبار ، وكل عقدة طرفية

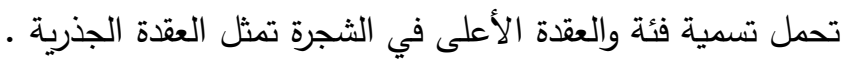

وفي سياق متصل يبين (Bankert et al.,2004, 1929)

أن شجرة القرار هي خوارزمية لاستخراج البيانات التي يمكن استخدامها في إيجاد نماذج التصنيف

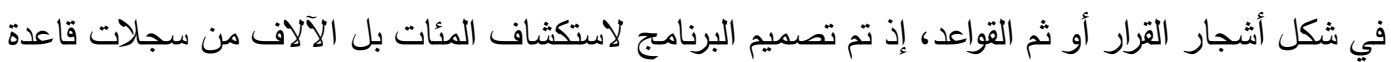

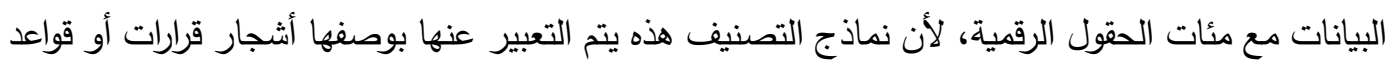

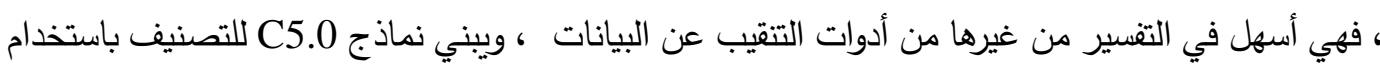

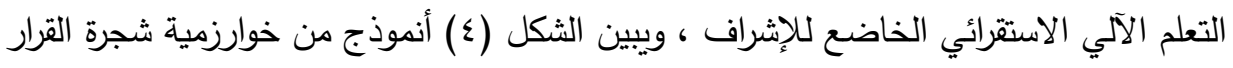

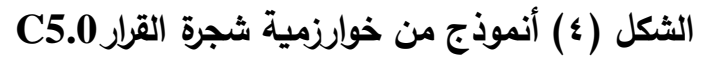

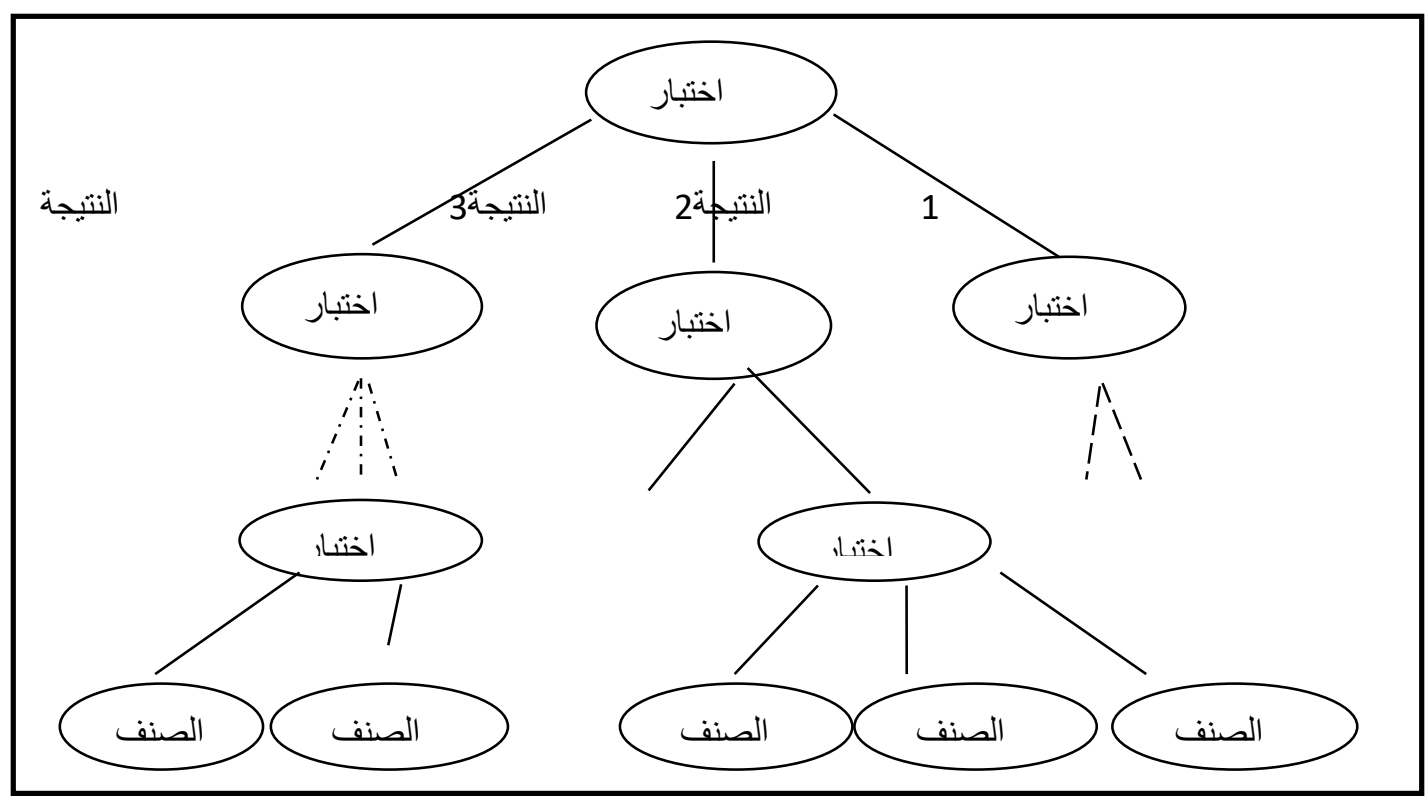

الثكل (1) أنموذج من خوارزمية شجرة القرار

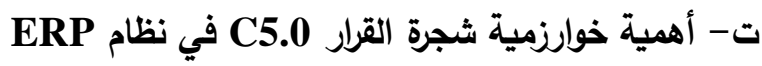

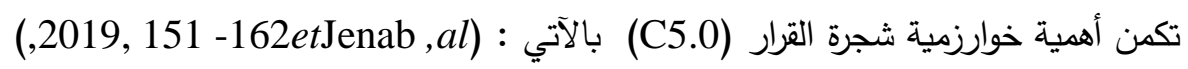

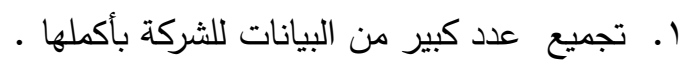

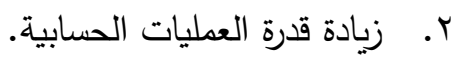

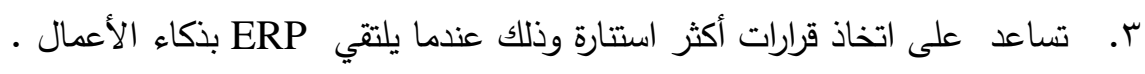

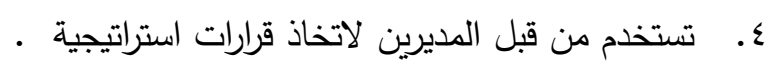


ه. تسهم في تقليل الكلف ، فضلاً عن تحسين العمليات وتحسين تراكم المعلومات بما يسهم في تعزيز

$$
\text { القدرة التنافسية . }
$$

7. تحسين جودة إعداد وجمع تقارير الثركة وتحليلها.

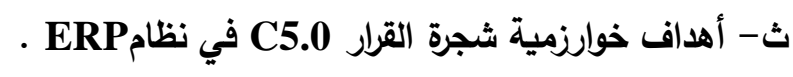

فقد بين ( Damij and Rajkovic,2015) أهدف خوارزمية شجرة القرار بالآتي :

1- تحسين المزايا التتافسية باستخدام تكنولوجيا المعلومات المتقدمة.

r- مواءمة قطاع البيع بالتجزئة مع استراتيجيات الثركة.

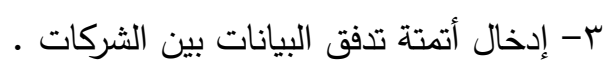

ج- مزايا خوارزمية شجرة القرار C5.0

يرى (Sun, 2017,8-11) أن مزايا أنموذج خوارزمية شجرة القرار C5.0 C5 التي تجعلها مناسبة

تمامًا لتصنيف بيانات الاستشعار عن بعد تتمثل بالآتي : نعرديا

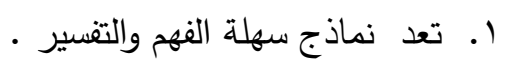

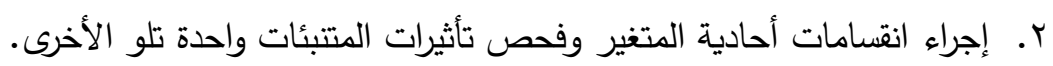

r. قادرة على التعامل مع مجموعة متتوعة من أنواع المتتبئات، وتتطلب القليل من إعداد البيانات .

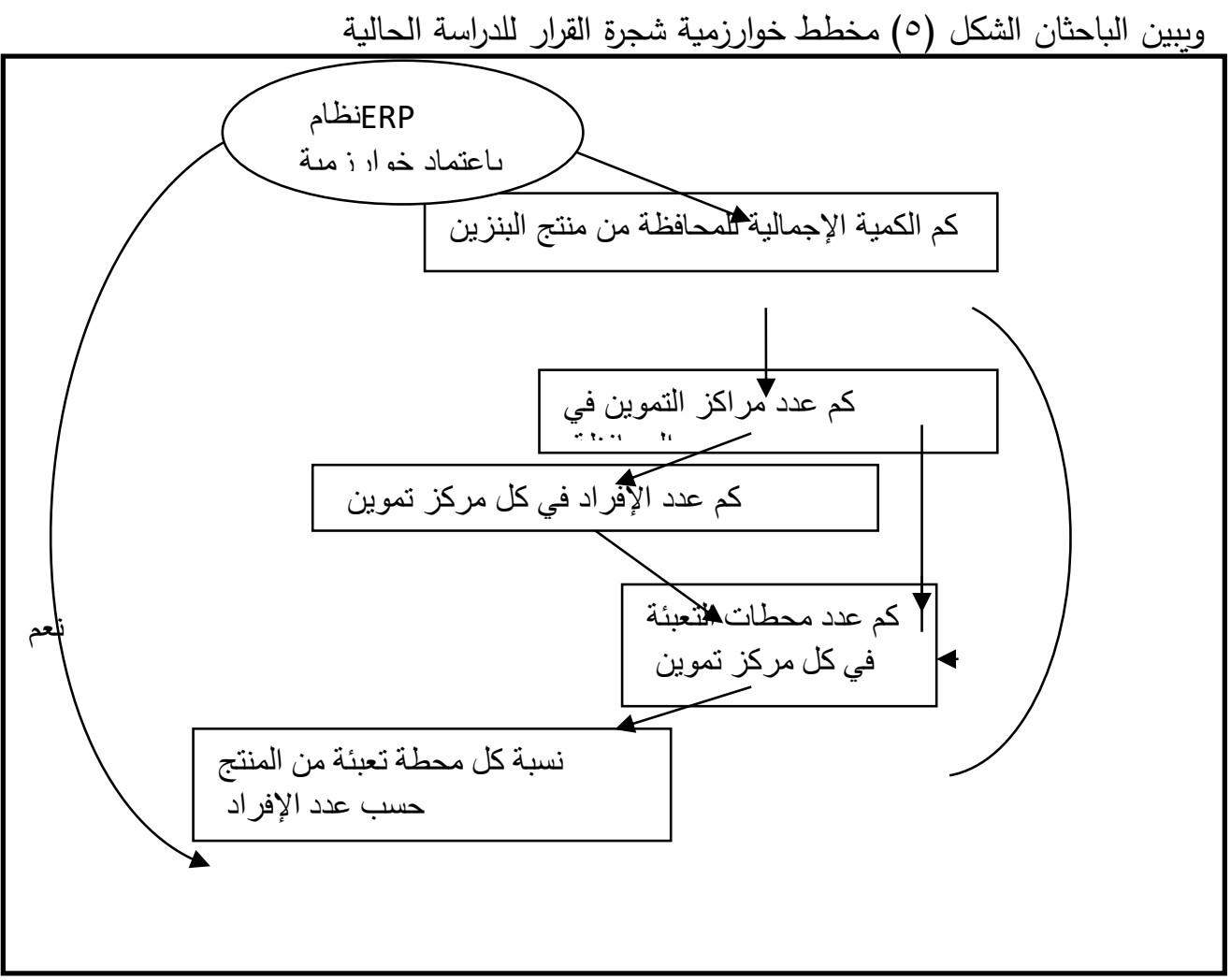

TANMIYAT AL-RAFIDAIN (P-ISSN: 1609-591X; E-ISSN: 2664-276X) تنمية الرافدين 
المصدر من إعداد الباحثين بتصرف على:

Wölfel, K., Smets, J. P., \& Strahringer, S. (2010). Automating erp package configuration for small businesses. In Proc. of IFIP International Conference on Research and Practical Issues of Enterprise Information Systems, Confenis, Natal/Brasil (pp. 25-27)

ح- وصف الأدوات وقاعدة البيانات واللغات المستخدمة في تصميم نظام ERP. 1- قاعدة البيانات: MySQL Database version 5.7.17 منصة حفظ وإدارة جداول المعلومات والمحتويات، يتم تتظيم هياكل قاعدة البيانات في ملفات فعلية الأمثل للسرعة. يوفر الأنموذج المنطقي ، مع كائنات مثل قواعد البيانات والجداول وطرائق العرض والصفوف لئن والأعمدة. r- لغة الاستعلام الهيكلية (Structured Query Language) هي لغة قياسية لتخزين البيانات ومعالجتها واستردادها في قواعد البيانات و SQL هي اللغة الموحدة الأكثر شيوعًا المستخدمة للوصول هلئل

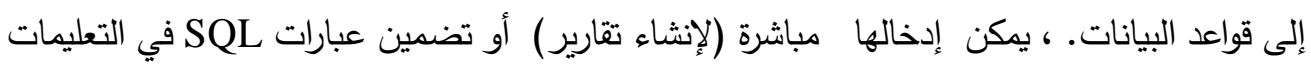

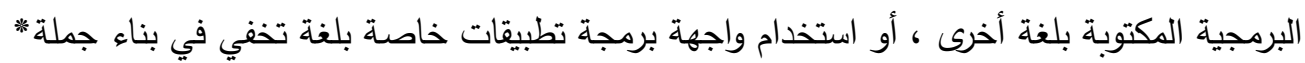

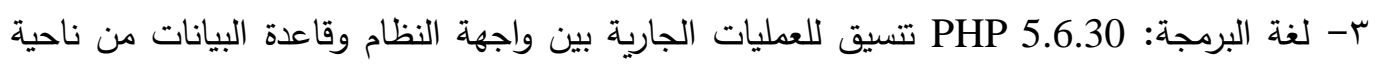
استعلام وإضافة وتعديل وحذف المعلومات وإجراء العبارات الثرطية وفلترة المعلومات المسترجعة، لئل

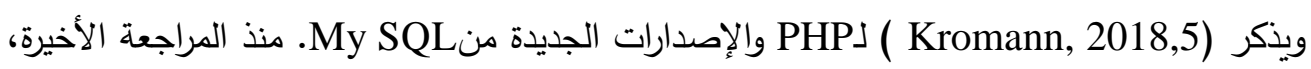
أصدرت PHP الإصدار V مع العديد من التحسينات اللغوية والتحسينات في الأداء، في بعض الحاتلات منات أكثر من ضعف السرعة واستخدام أقل من نصف الذاكرة مقارنة بـ SPHP 5.6 My SQL ع- لغة تصميم واجهات الموقع HTML 5 تصميم الجداول والنوافذ والحقول والقوائم الخاصة بالموقع والخاصة بالجهة التي سيتعامل معها مستخدم النظام. ه- لغة التتسيق CSS 4 لإضافة مؤثرات جمالية وتتسيقية على جميع واجهات الموقع، ويعمل كإضافات *لغة (.html) ع - مراحل تصميم وتثغيل نظام ERP المقترح في الثركة العامة لتوزيع المنتجات النفطية يبين الباحثان مراحل تصميم نظام ERP المقترح لتوزيع المنتجات النفطية ويتضمن الآتي :

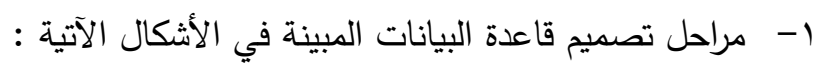

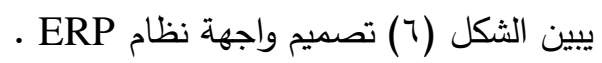

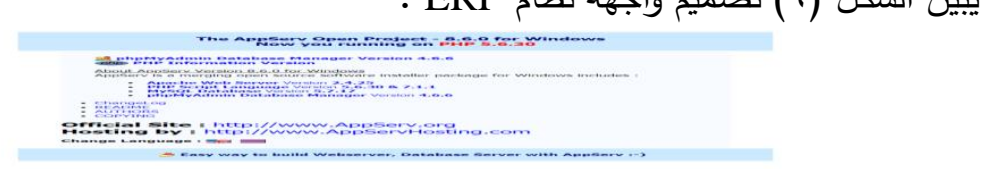

يبين الثكل (V) واجهة دخول للنظام المقترح 
تصميم نموذج نظام مقترح لتخطيط موارد المشروع ......... الجبوري والجبوري

يبين الثكل (^) جدول قاعدة البيانات

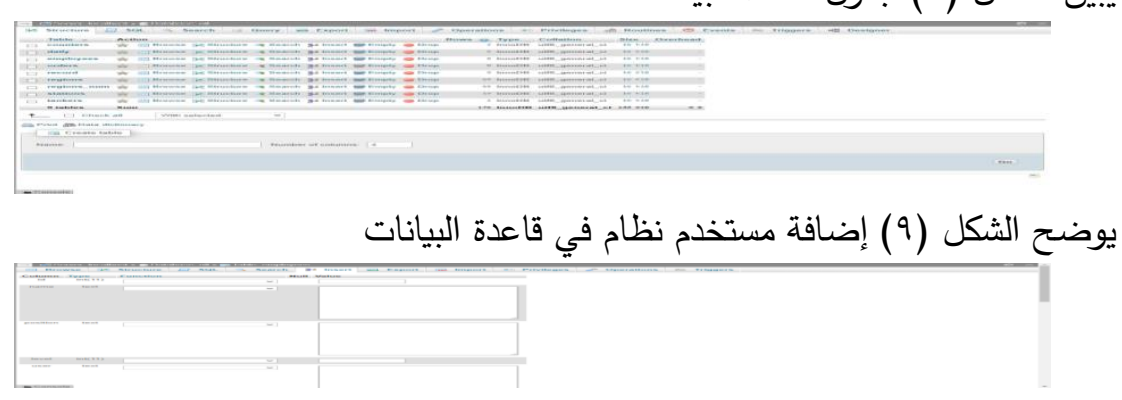

http://www.mysql.com الثكل(· (1) جدول مستخدمي النظام

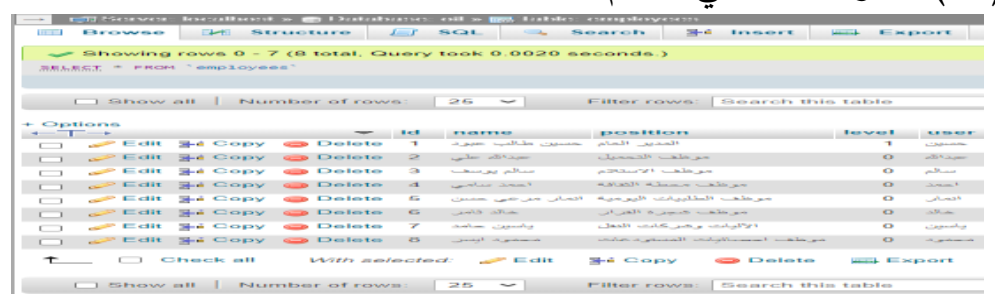

r- مراحل اللغة البرمجية المستخدمة في تصميم النظام المبينة في الأشكال الآتية : لإل

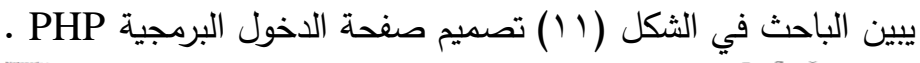

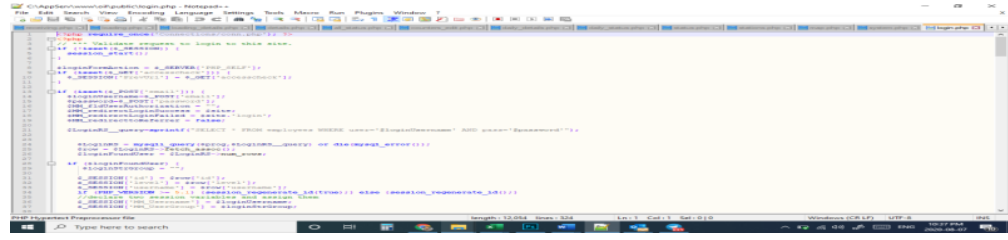

r- مراحل تثغيل نظام ERP المقترح الذي تم تشغيله وفق آلية توزيع المنتجات النفطية والذي يتكون من ثمانية مداخل مبينة في الإثكال الآتية: 1- الواجهة الرئيسة، المستخدم مدير عام الثركة الذي يثرف على الإنى كافة المستخدمين (موظف إعداد

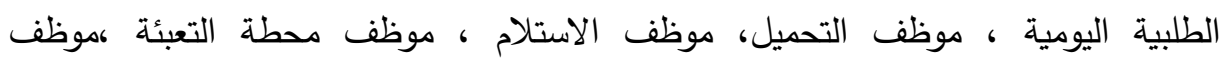

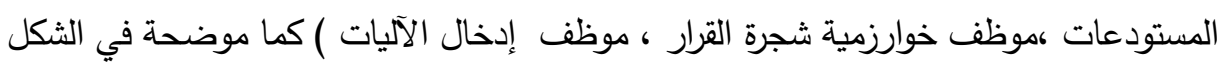


تصميم نموذج نظام مقترح لتخطيط موارد المشروع ............ الجبوري والجبوري
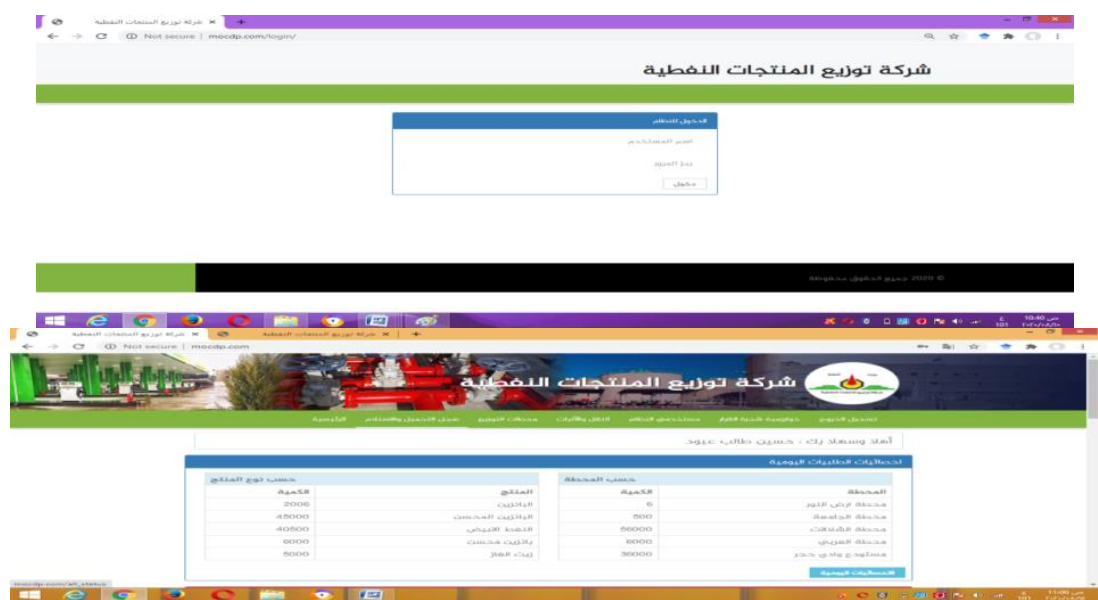

الثكل (Y ( ) واجهة مدير عام الشركة

r- واجهة موظف إعداد الطلبية اليومية، مهامه إعداد الطلبية اليومية للمنتجات النفطية وتوزيعها على المحطات والمستودعات بحسب الاحتياج بعدها تظهر لاى نافذة موظف التحميل بثكل تلقائي بعد إعطائها حفظ يبين الثكل (r ا ) فتح واجهة موظف إعداد الطلبية

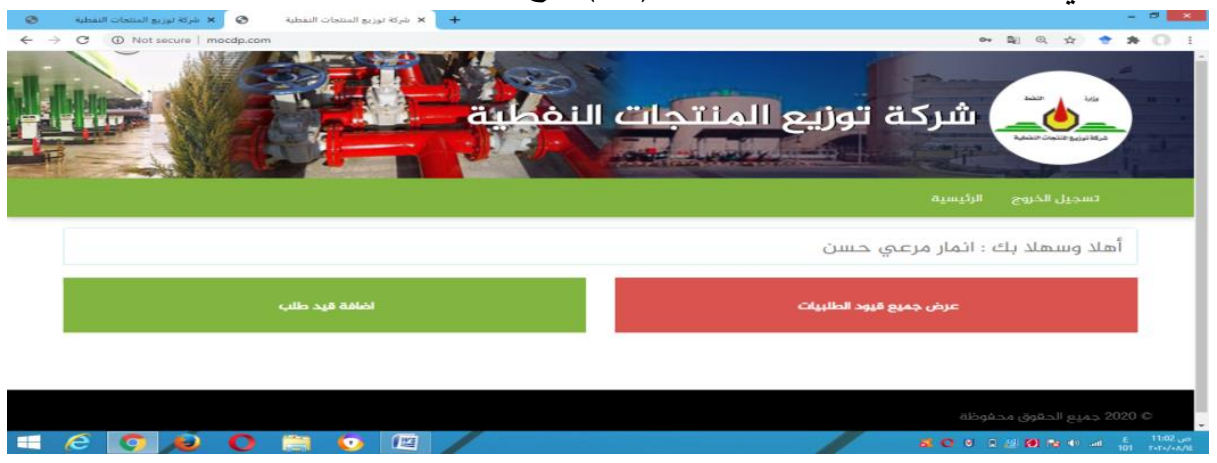

الثكل (r ا ) نافذة موظف إعداد الطلبية

تبين من خلال الواجهة إعطاء خيارين، الأول عرض جميع قيود الطلبيات وعند فتح الإيعاز تفتح

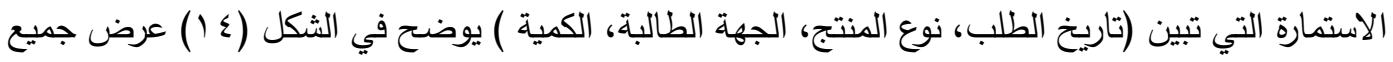

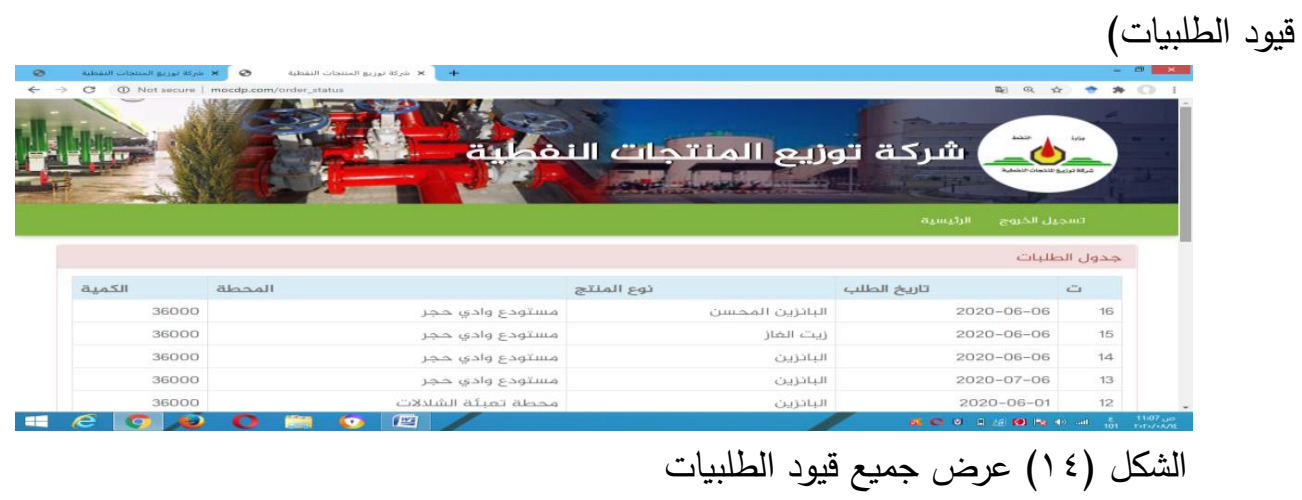

TANMIYAT AL-RAFIDAIN (P-ISSN: 1609-591X; E-ISSN: 2664-276X) تنمية الرافدين 
تصميم نموذج نظام مقترح لتخطيط موارد المشروع ............ الجبوري والجبوري

أما عند فتح الإيعاز إضافة قيد طلب يوضح الثكل (ب ( ) طلب كمية جديدة ليوم جديد أو ملحق

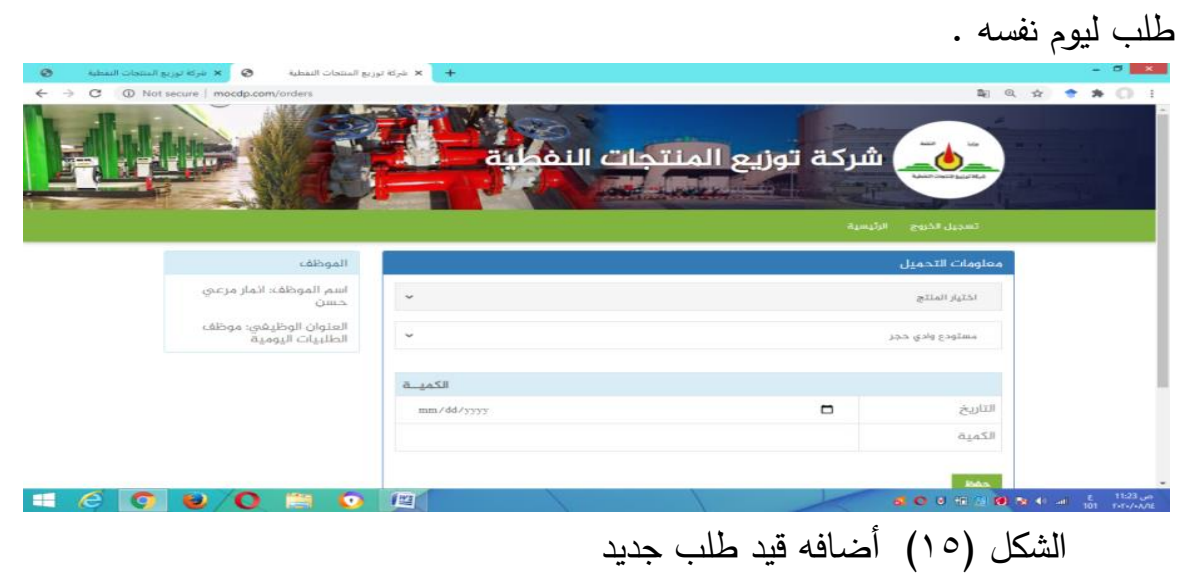

r- نافذة موظف التجهيز مهامه بعد استلام الإيعاز من موظف إعداد الطلبية يتم تجهيز الطلبية

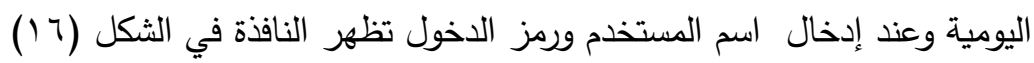
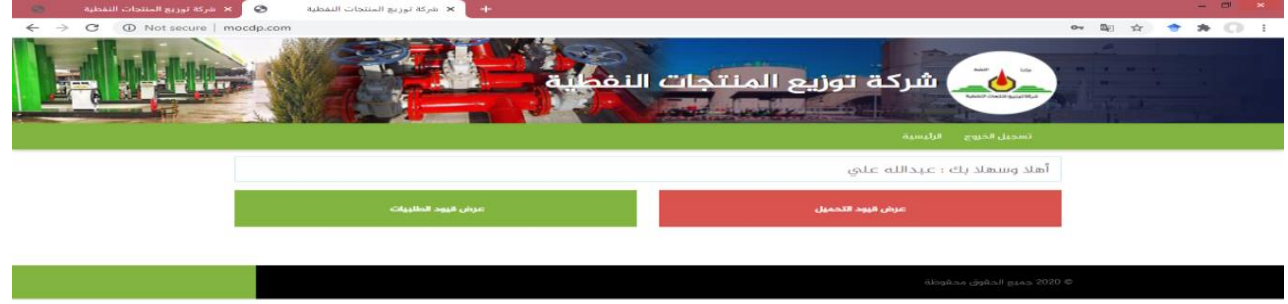

الشكل (7 ( ) نافذة موظف التجهيز

وعند فتح نافذة عرض قيود التحميل في الثكل أعلاه تظهر القائمة في الثكل (IV) يبين في حقل

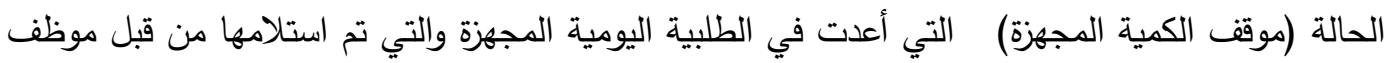

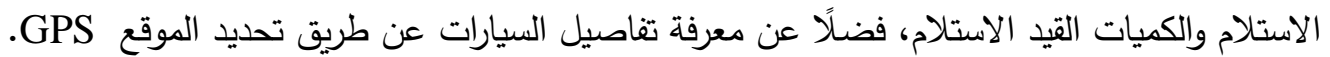

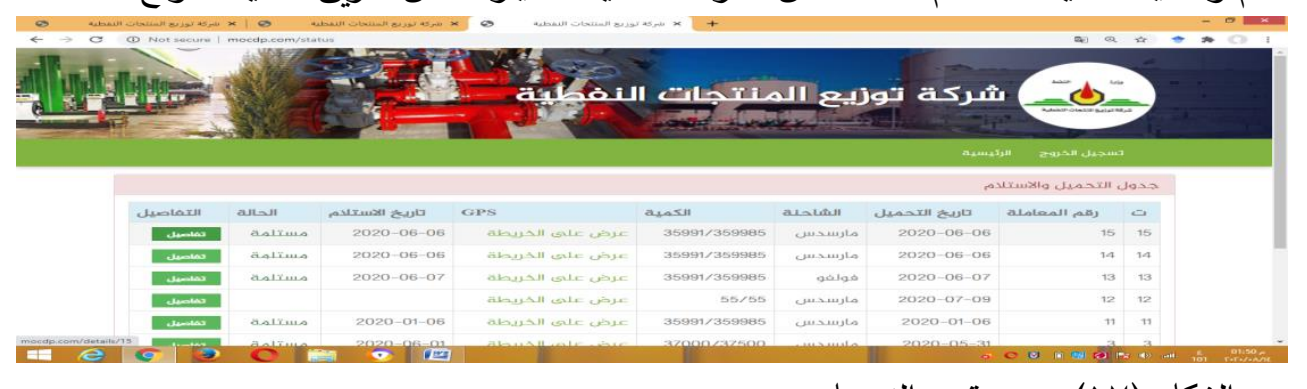

الثكل (lV) عرض قيود التحميل

أما عند فتح عرض قيود الطلبات في الثكل (7 (1) تظهر النافذة في الثكل (1) (1) هي جدول الكميات التي أعدت من لدن موظف الطلبية اليومية.

TANMIYAT AL-RAFIDAIN (P-ISSN: 1609-591X; E-ISSN: 2664-276X) تنمية الرافدين 
تصميم نموذج نظام مقترح لتخطيط موارد المشروع ........... الجبوري والجبوري

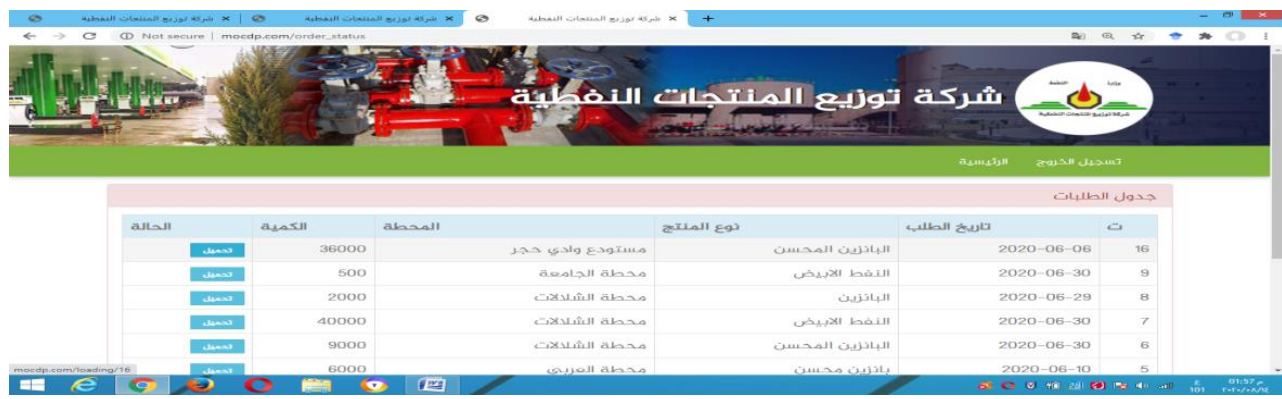

$$
\text { الثكل (1) إ) عرض قيود الطلبيات }
$$

أما عند الضغط على الزر تحميل في الثكل (1) (1) تظهر النافذة في الثكل (9 (1) لتجهيز الكمية

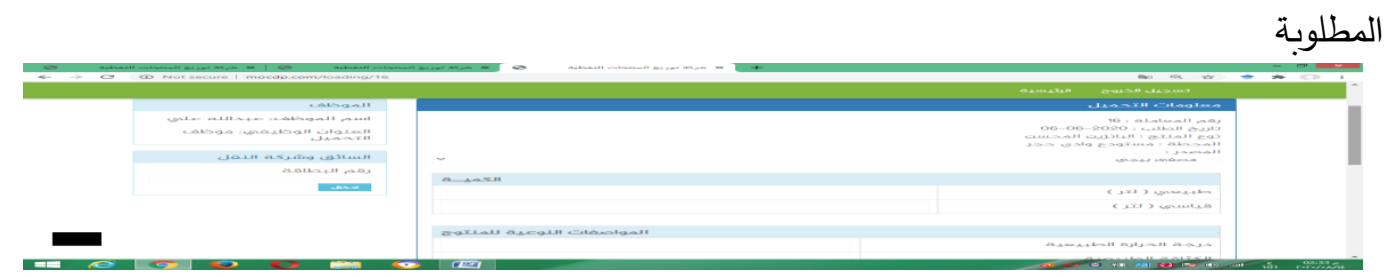

الثكل (9 (1) قائمة معلومات الإدخال للتجهيز

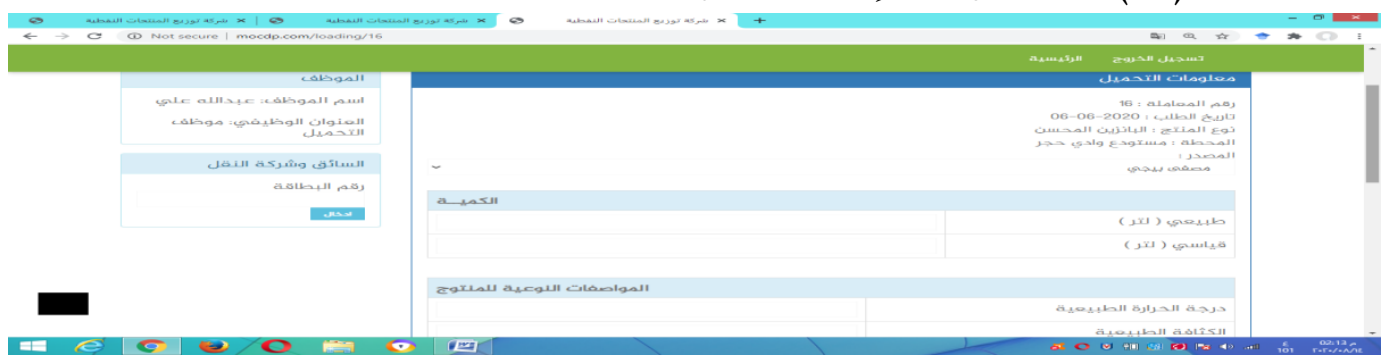

ع- واجهة موظف الاستلام عند فتح النافذة يظهر الثكل (·r)

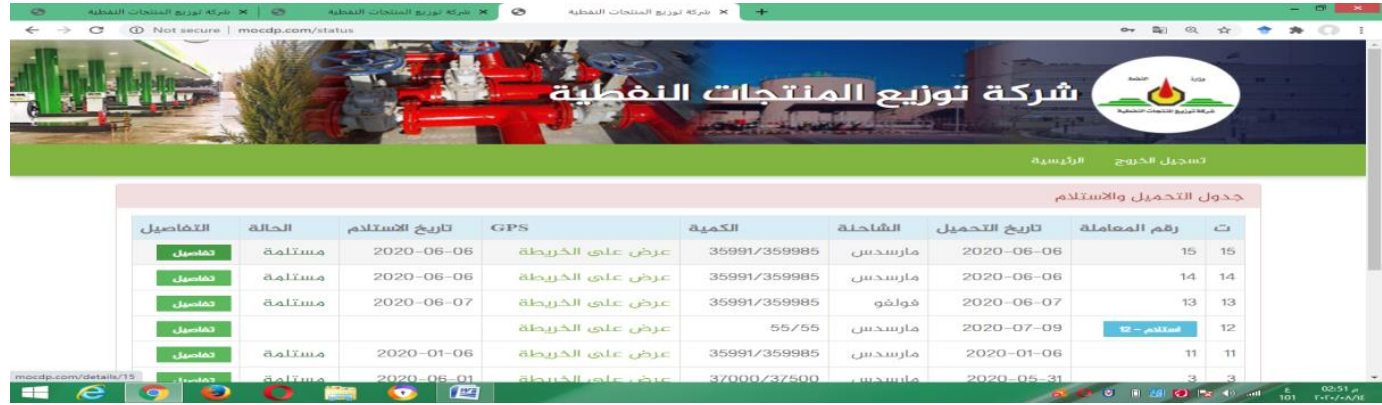

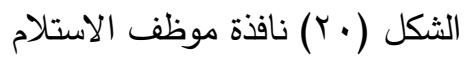

من خلال الثكل أعلاه وعند الضغط على التفاصيل في استمارة الاستلام يتم فتح الاستمارة في

$$
\text { الشكل (Yl) التي تبيين تفاصيل (المنتج والكمية وقت التجهيز ...الخ). }
$$

TANMIYAT AL-RAFIDAIN (P-ISSN: 1609-591X; E-ISSN: 2664-276X) تنمية الرافدين 
تصميم نموذج نظام مقترح لتخطيط موارد المشـروع .......... الجبوري والجبوري

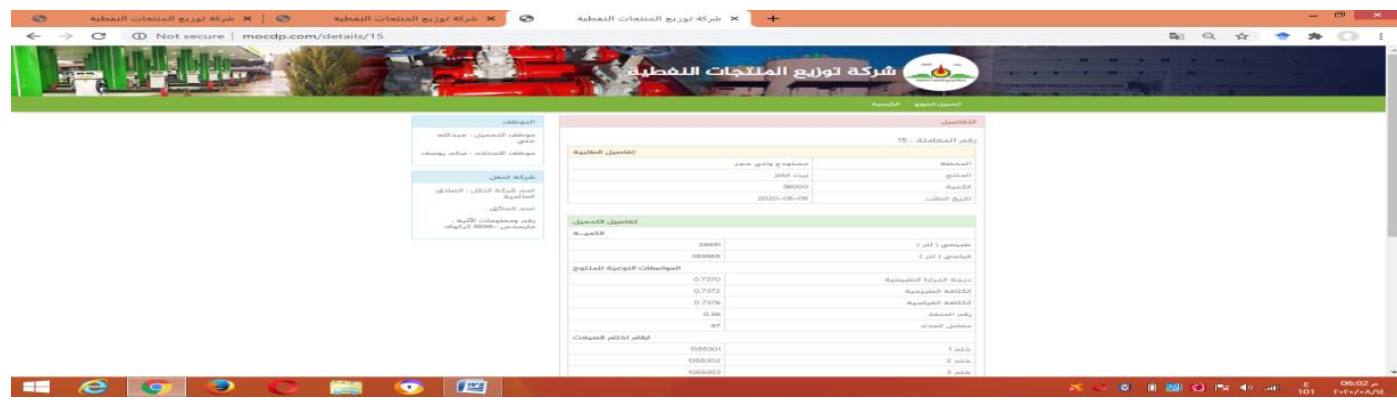

$$
\text { الشكل (Y) تاصيل استمارة الاستلام }
$$

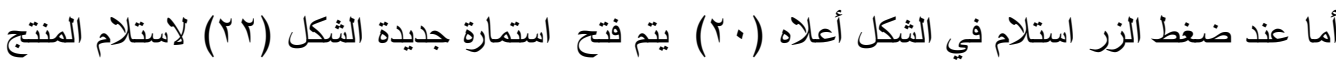

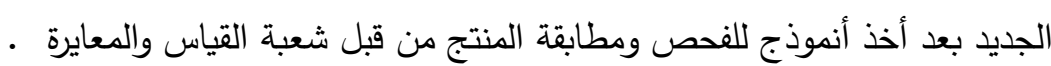

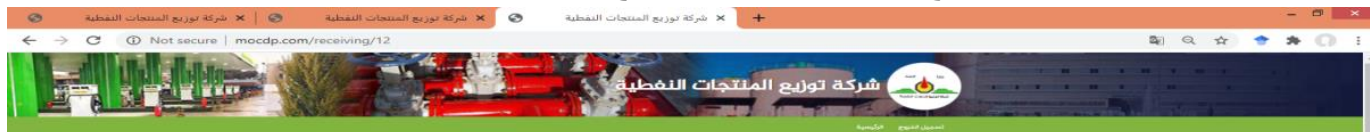

IE $e$ e

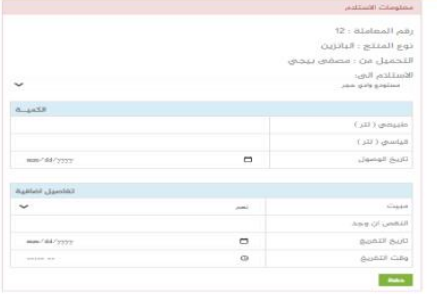

$$
\text { الثكل (Yr) استمارة استلام منتج جديد }
$$

5- واجهة موظف محطة تعبئة الوقود بعد استلام الإيعاز من موظف الاستلام يتم تفريغ المنتج في

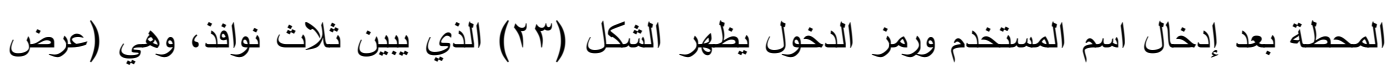
جدول التقرير اليومي ، عرض جدول قراءة العدادات، إضافه قراءة عدادات )

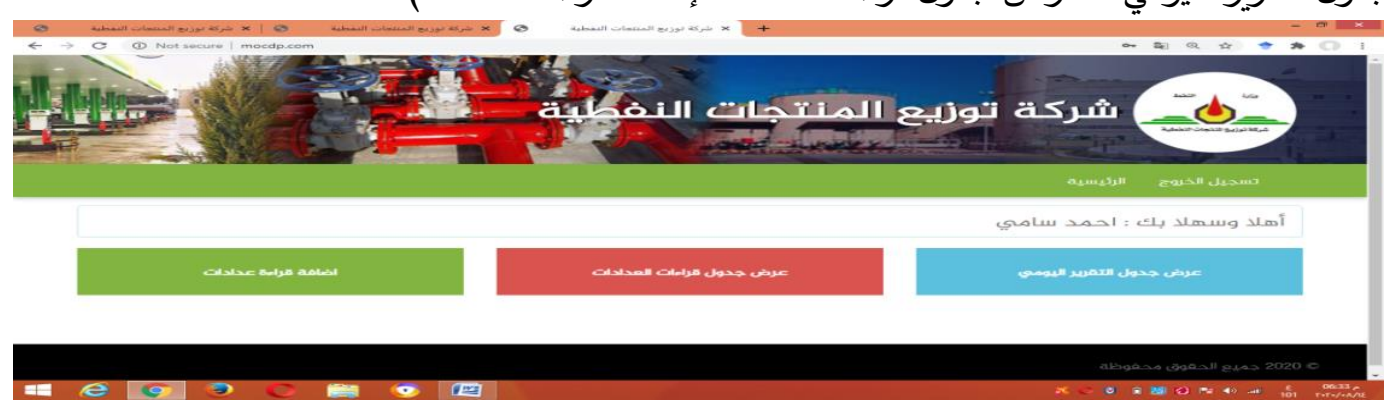

$$
\text { الثكل (Tr) نافذة موظف تعبئة توزيع المنتجات النفطية }
$$

عند الضغط على نافذة عرض جدول التقرير اليومي تظهر تفاصيل المنتجات والكميات بحسب التاريخ (المبيعات، الموجود الحالي ، الوارد) التي تظهر في الثكل (rr) وتظهر القائمة في الثكل أدناه (ع ب) . 
تصميم نموذج نظام مقترح لتخطيط موارد المشروع ........... الجبوري والجبوري

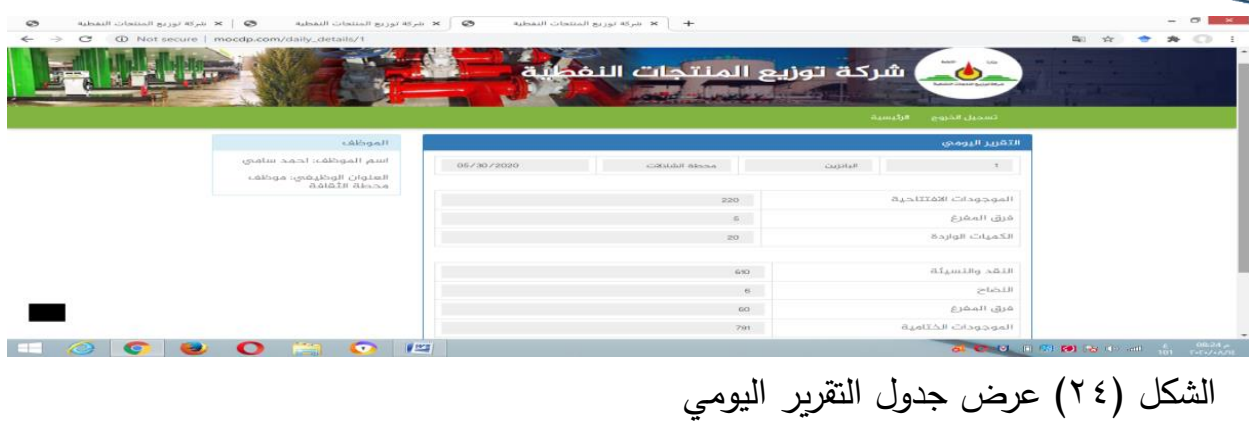

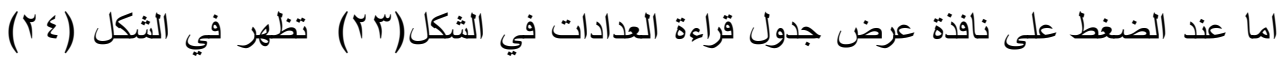

$$
\text { جدول قراءات العدادات للمنتجات }
$$

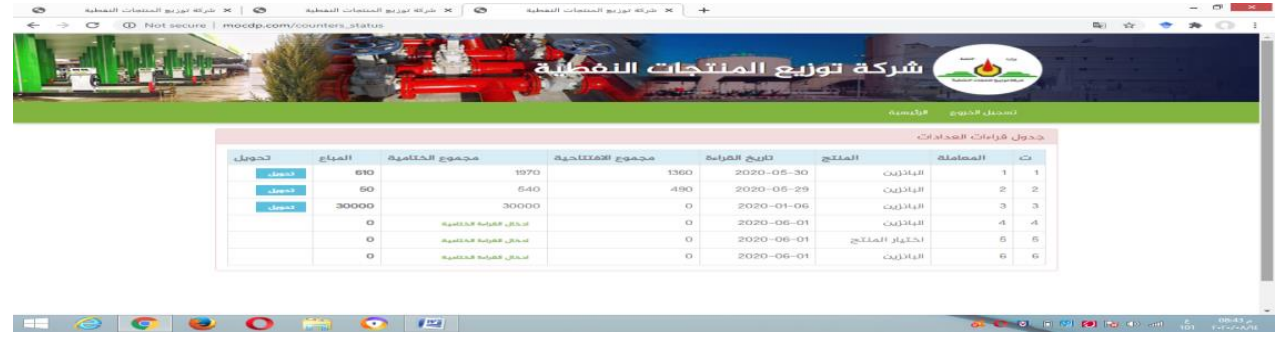

$$
\text { الثكل (ع r) جدول قراءات العدادات للمنتجات }
$$

وفي سياق متصل عند الضغط على الزر تحويل في الثكل (؟) بظهر الاستمارة في الثكل (Yo)

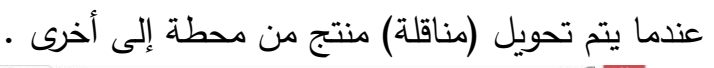

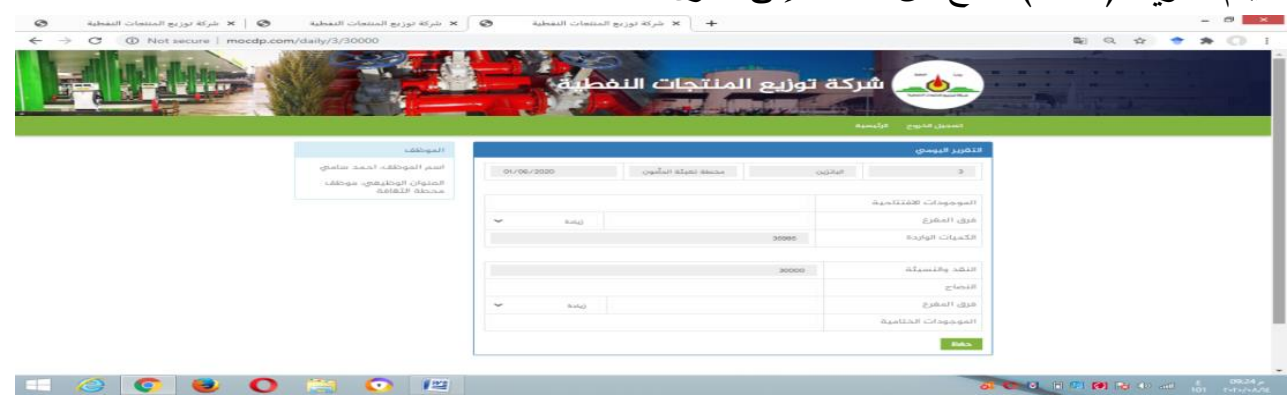

$$
\text { الثكل(Y0) تحويل (مناقلة) منتج من محطة إلى أخرى . }
$$

وفي سياق متصل عند الضغط على إضافة قراءة العدادات في الثكل(ro) تظهر في الثكل(ب r) .

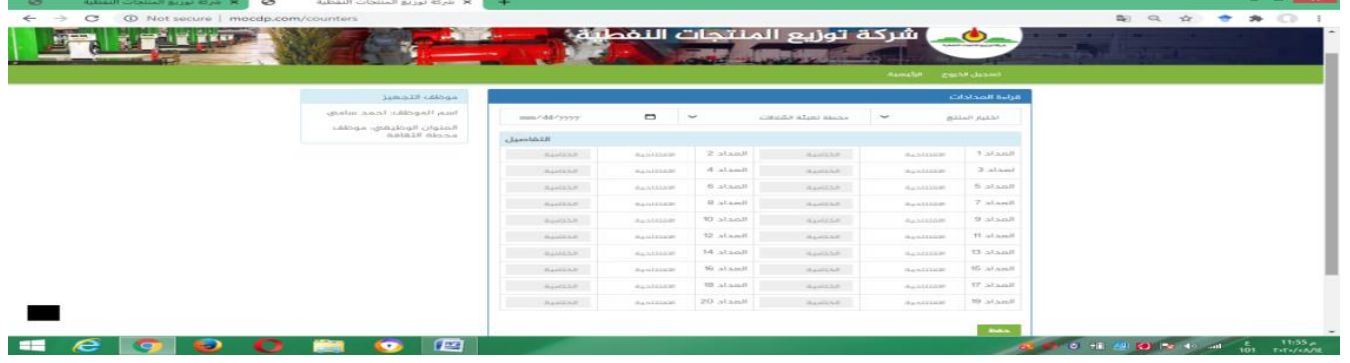

الثكل(†) بإضافة قراءة العدادات في محطة التبعئة

TANMIYAT AL-RAFIDAIN (P-ISSN: 1609-591X; E-ISSN: 2664-276X) تنمية الرافدين 
تصميم نموذج نظام مقترح لتخطيط موارد المشروع ......... الجبوري والجبوري

6- واجهة مستخدم موظف مستودع الحزين، بد الإيعاز من موظف إعداد الطلبية اليومية وموظف

التجهيز والاستلام يتم استلام المنتج في المستودع ويكون خزينًا احتياطيًا يجهز لمحطات التعبئة عند الاحتياج

في حالة توقف المصافي أو حدوث ظروف قاهرة يبين الثكل (rV)

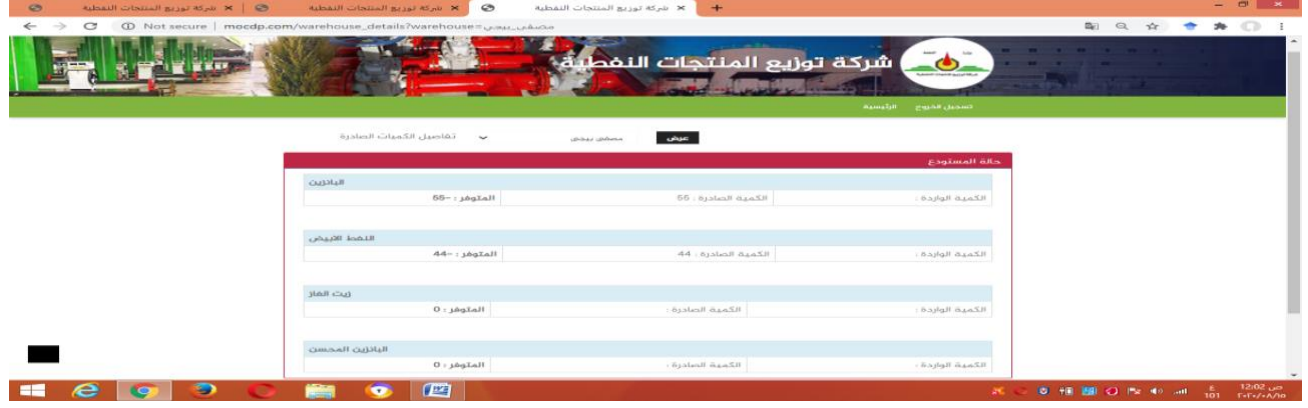

الثكل (YV) واجهة موظف مستودع الخزين

7- نافذة مستخدم خوارزمية شجرة القرار التي تستخدم لتوزيع الحصص على على أساس الكثافة السكانية

الذي يبين في الثكل (r^)

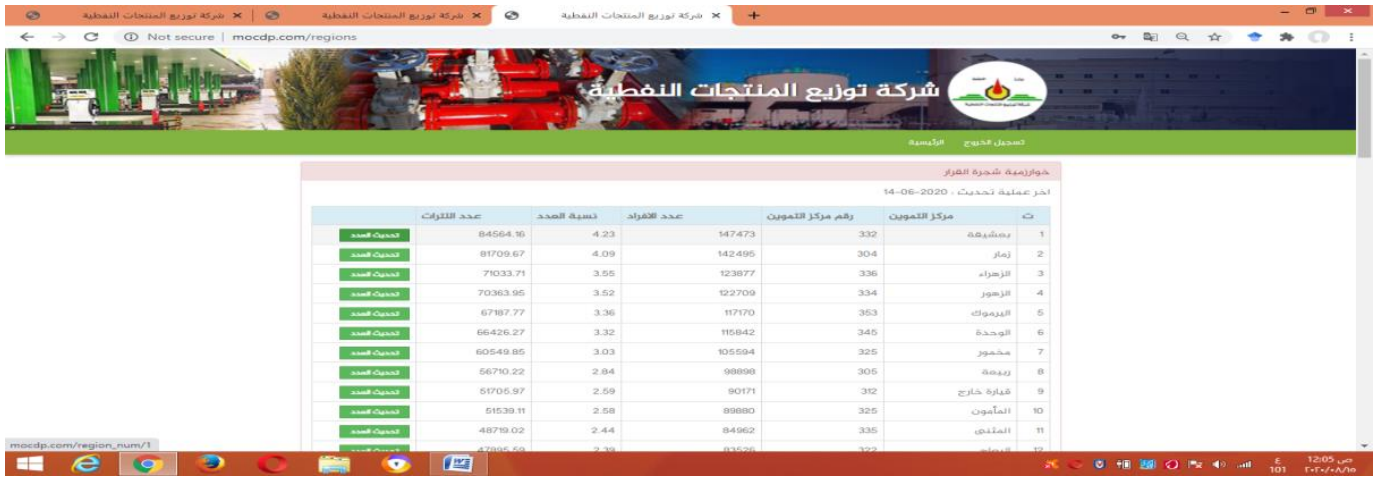

الشكل (Y^) نافذة مستخدم خوارزمية شجرة القرار

8- نافذة موظف إدخال بيانات الآليات المستخدمة في نقل المنتجات النفطية وفق بطاقة تعريفية

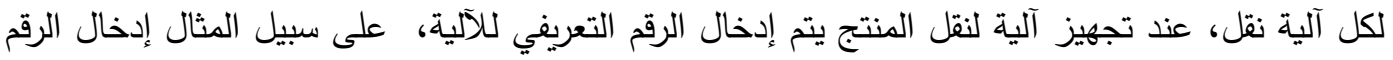

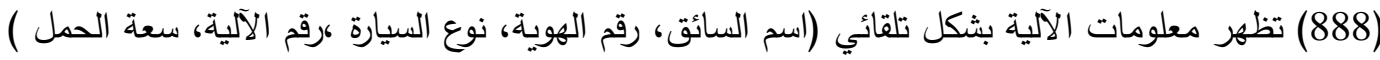

كما مبين في الثكل (rq)

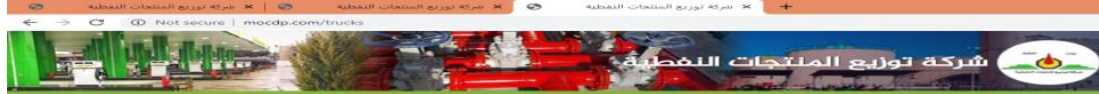

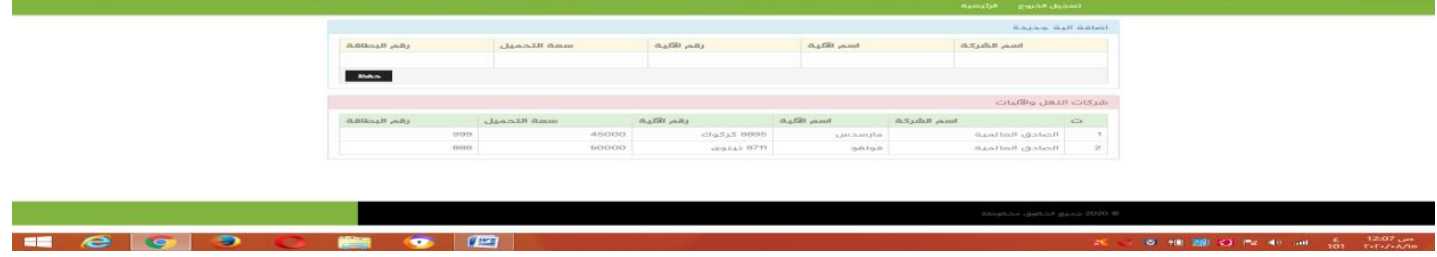

الشكل (•r) نافذة موظف إدخال بيانات آليات نقل المنتجات النفطية 


$$
\begin{aligned}
& \text { ع - الاستنتاجات والمقترحات والتوصيات } \\
& \text { أولا : الاستنتاجات النظريـة }
\end{aligned}
$$

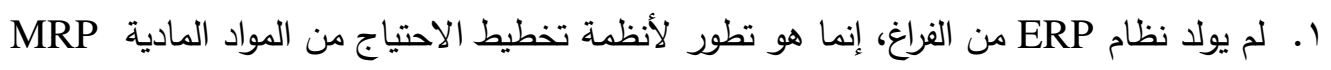

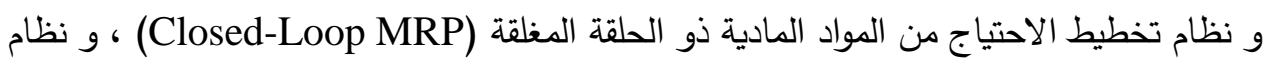

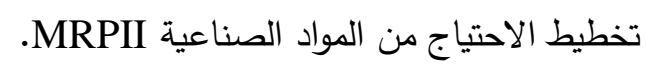
r. هناك نقص كبير وواضح في الأدبيات العربية الخاصة بنظام ERP وخصوصاً فيما يرتبط باستقصاء

$$
\text { دوافع تبني نظام ERP في الثركات العربية والعراقية. }
$$

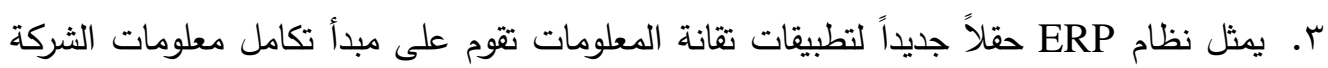

داخل قاعدة بيانات موحدة من خلال عدد من النماذج تخدم المستويات في الشركة جميعاً.

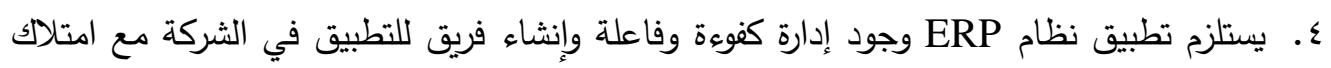

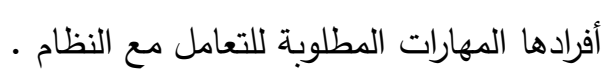

ه. يؤدي فهم دوافع تبنّي نظام ERP دوراً مهماً في نجاح تشغيله وقبل ذلك التصميم المناسب له،

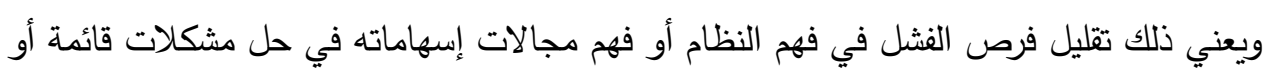

$$
\begin{aligned}
& \text { فهم عناصر حيوية تسهم في نجاح التطبيق. } \\
& \text { ثانيا :الاستنتاجات العملية }
\end{aligned}
$$

من خلال المعايثة الميدانية التي أجراها الباحث في شركة توزيع المنتجات النفطية والمقابلات مع النعائ المسؤولين فيها، ونتائج قائمة الفحص المتعلقة بدوافع تبنّي تصميم نظام ERP ونتائج تثغيل النظام المقترح

$$
\text { توصل الباحث إلى الاستتاجات الآتية : }
$$

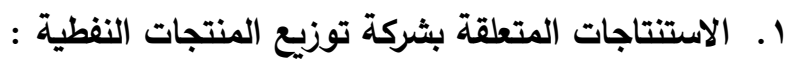

أ- كثفت نتائج تحليل الإدراك الأولي للمديرين حول موضوع الدابعة الداستة أنه ضمن المستوى المقبول وفي الاتجاه الإيجابي، مما يؤكد أن المبحوثين يدركون دوافع تبني نظام ERP ومزايا تصميمه وتثغيله.

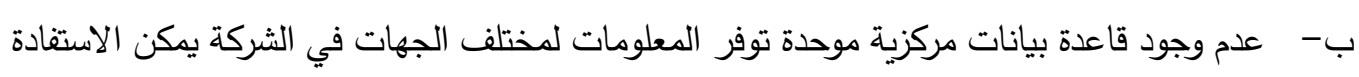
منها في اتخاذ القرارات، إذ يكون جمع البيانات بشكل منفرد. ت- - يتوافر في كل قسم من أقسام الثركة حاسوب مع مشغل إلا أنهم لا يستعملونها إلا لطبع الوثائق

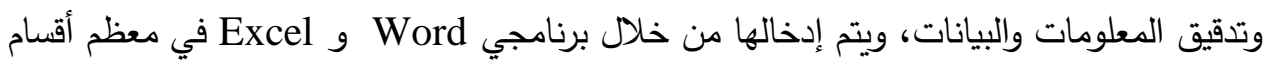
الثركة. ث- - يتوافر في قسم التوزيع برنامج مصدم على برنامج Access و Excel فيه أنموذج إدخال ، تم

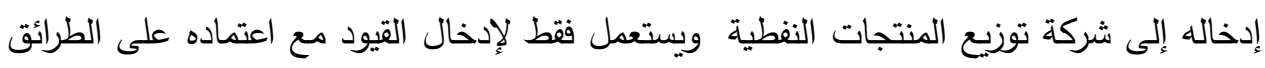

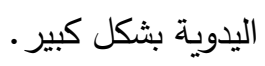


ج- آلية توزيع المنتجات النفطية من التحميل (الإنتاج) إلى توزيع المنتجات يتم العمل به بالطرائق التقليدية (الورقية).

ح- عدم وجود قاعدة بيانات مشتركة تربط آلية توزيع المنتجات النفطية من الإنتاج إلى التوزيع • r- الاستنتاجات المتعلقة بالتحليل الاحصائي لقائمة الفحص :

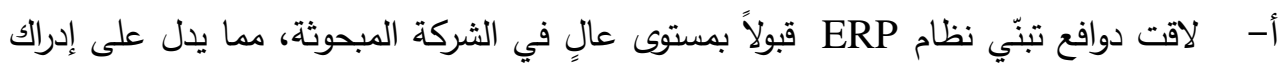
حقيقي للحاجة إلى نظام ERP وعبر عن ذلك بوجود التزام الإدارة العليا في الثركة العامة لتوزيع المنتجات النفطية في تقديم الدعم لنجاح تطبيق نظام ERP ، وتوفير الموارد اللازمة لتصميم وتثغيل النظام مع وضع إستراتيجية فعّالة للسيطرة على إعادة هندسة عمليات الأعمال تباستمرار لتطبيق نظام ERP. ب- - تبين من خلال نتائج تشغيل نظام ERP، أن هذه النتائج لاقت قبولاً بمستوى عالٍ في الثركة

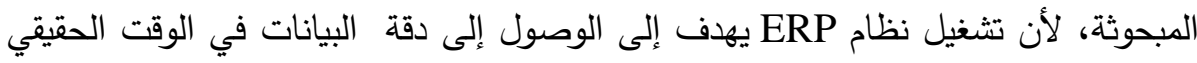
وأتحاذ القرار المناسب من خلال الاطلاع على كافة العمليات، ويحقق أداء أفضل في تقليل

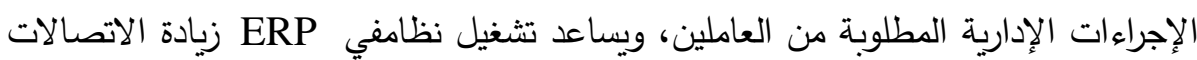

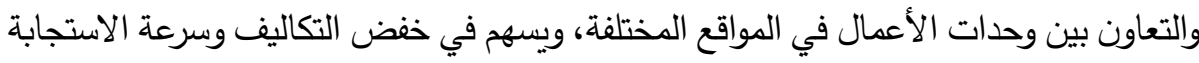

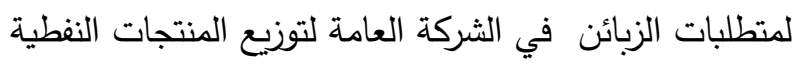

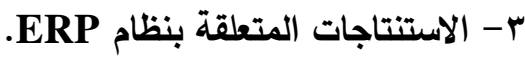
أ- - ظهر أن استخدام نظام ERP، سيساعد الثركة المبحوثة في رفع مستوى أدائها ، من خلا لـ السيطرة على حركة التعاملات اليومية. ب- أتضح أن تصميم وتشغيل نظام ERP يساعد في تحقيق رضا المستفيدين من خلال تخليصه من عبء العمل الورقي (النظم التقليدية ) واستبداله بالنظم المعاصرة (الالكتروني) وإمكانية حفظها بواسطة الأقراص المرنة ، مما يؤدي إلى تقليص المساحات المخصصة لخئه لخزن الوثائق

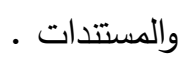
ت- تبين أن نظام ERP سيمكن العاملين في الثركة المبحوثة من سهولة الحصول على التقارير

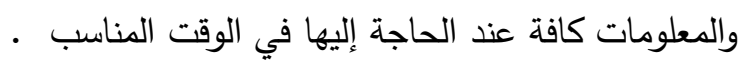
ث- يساعد نظام ERP المدراء في اتخاذ القرار في الوقت المناسب من خلال الاطلاع على العمليات كافة العمليات وانسيابيتها والحصول عليها في الوقت المناسب . ج- ساعد تصميم وتثغيل نظام ERP في إيجاد نظام معلومات متكامل لعمليات توزيع المنتجات النفطية ح- تبين أن تصميم وتثغيل نظام ERPف ي توزيع منتج (البنزين) على المحطات على أساس الكثافة السكانية. 
خ- - أسهم تصميم وتشغيل نظام ERP في ربط العمليات في نظام واحد متكامل لكافة عمليات

$$
\text { الشركة. }
$$

د- ساعد تصميم وتثغيل نظام ERP ربط أجهزة مراقبة لسيارات نقل المنتج من الإنتاج إلى

$$
\text { • التوزيع (المقان }
$$

$$
\text { ثانياً:المقترحات }
$$

في ضوء الإطار الميداني للدراسة وما أظهرته النتائج، واستكمالاً لمتطلبات الدراسة سيتم عرض مجموعة

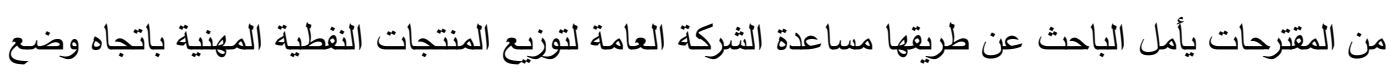

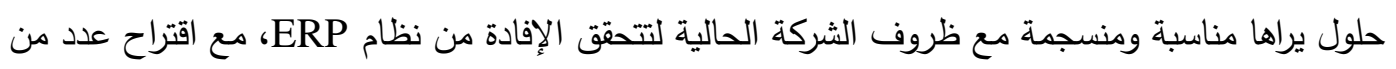

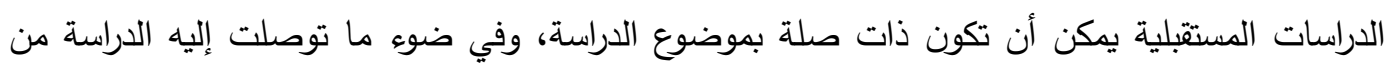

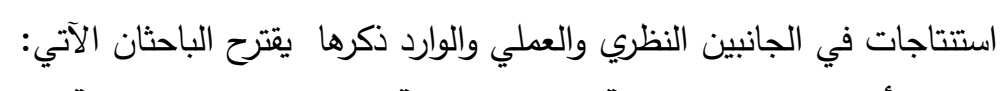
أ. المقترحات الموجهة إلى إدارة شركة توزيع المنتجات النفطية .

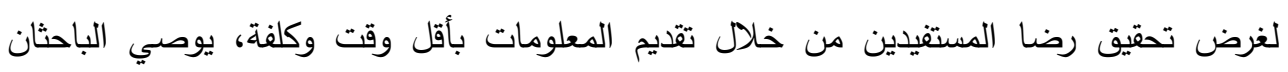

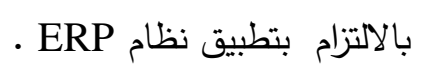

1. المقترح الأول : إثراك المديرين جميعهم بفاعلية في كل خطوة من خطوات تطبيق

\section{نظام ERP}

$$
\text { - آليات التنفيذ. }
$$

• متابعة الإدارة العليا بفاعلية المديرين في كل خطوة من خطوات تطبيق ل

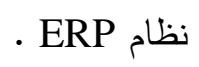

• تشكيل شعبة إدارية ترتبط بالإدارة العليا يناط بها الإثراف على سير تطبيق النظام المقترح

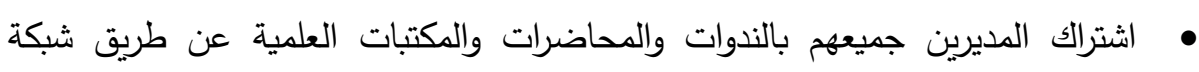

$$
\text { الإنترنت }
$$

• • نشر الملصقات الجدارية في الشركة عن مفاهيم نظام ERP والمزايا المتحققة من تطبيقه

r. المقترح الثاني : تحديد صلاحيات ومسؤوليات مختلف الأطراف ذات العلاقة بتطبيق نظام ERP. - آليات التنفيذ.

• من خلال توجيهات الإدارة العليا بتحديد الصلاحيات للإطراف ذات العلاقة بتطبيق نظام

.ERP

r. المقترح الثالث : ضرورة توجيه أفراد متخصصين (محللين ومبرمجين ) تكون مهمتهم الإشراف

$$
\text { على نظام ERP وإدارته . }
$$

- آليات التنغيذ.

• من خلال متابعة الإدارة العليا لفريق العمل في الإشراف على نظام ERP وإدارته . 


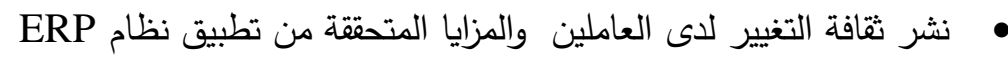

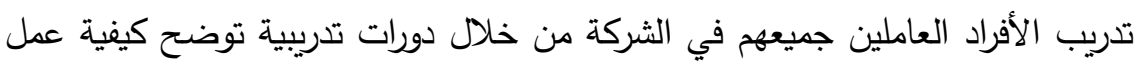
نظام ERP ومناهج تتسجم مع أهدف النظام لتسهيل عمليات التطبيق. دعم الإدارة العليا للعاملين على نظام ERP من خلام ألاف مكافأة تثجيعية ؛. . المقترح الرابع : بناء شبكة اتصال داخلية بين أقسام الثركة جميعها.

$$
\text { - آليات التنفيذ. }
$$

• دعم الإدارة العليا في توفير الموارد اللازمة وفريق العمل المناسب .

• • تشكيل فريق عمل من المبرمجين في الثركة بمتابعة الإدارة العليا.

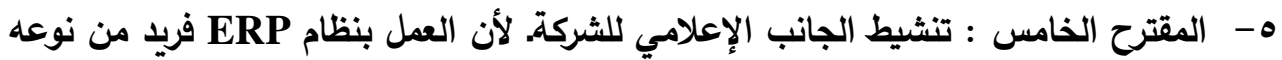

$$
\text { في البيئة العراقية. }
$$

• عديث المعلومات الخاصة بالشركة على الموقع الإلكتروني الخاص بالشركة.

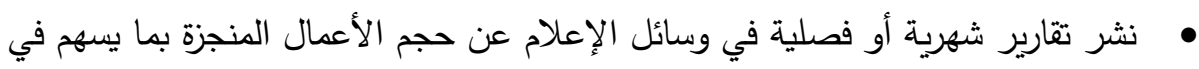

تعزيز الثقافة المجتمية نحو بمزايا تطبيق نظام لنعP

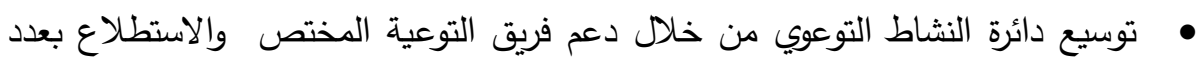

$$
\text { أكبر من الوسائل من بوسترات وغيرها من الوسائل. }
$$

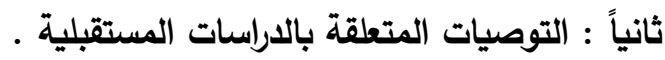

يقترح الباحثان أن يكون اهتمام الباحثين بموضوع نظام ERP ويقترحان عدد من المجالات تصلح

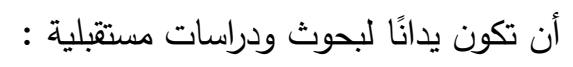

ا- أثر نظام ERP في تعزيز الأداء المنظمي دراسة حالة في شركة توزيع المنتجات النفطية r- أثر استخدام نظام ERP في زيادة الإنتاجية دراسة حالة في الثركة العامة للسمنت الثمالية

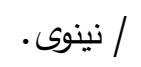

r- المعوقات التي تواجه الشركات في تطبيق نظام تخطيط موارد الشركة ERP دراسة استطلاعية لآراء المديرين لمجموعة من الشركات النفطية في محافظة نينوى.

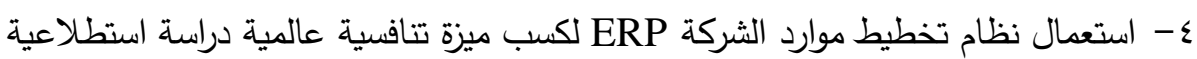
لآراء المديرين لمجموعة من الثركات النفطية في محافظة نينوى.

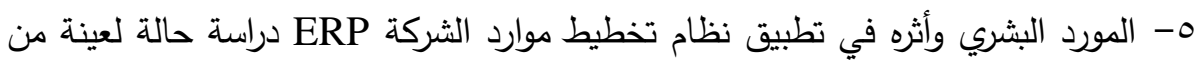
شركات وزارة النفط. צ- الفجوة بين تطبيق نظام تخطيط موارد الثركة ERP وتعليمه دراسة حالة في مصفى الصمود صلاح الدين. 


$$
\begin{aligned}
& \text { تصميم نموذج نظام مقترح لتخطيط موارد المشروع } \\
& \text { الجبوري والجبوري }
\end{aligned}
$$

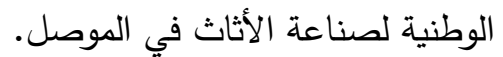

\section{References}

\section{A- Dissertations \& Thesis}

1- Bakır, B., Batmaz, İ. N. C. İ., Güntürkün, F. A., İpekçi, İ. A., Köksal, G. Ü. L. S. E. R., \& Özdemirel, N. E. (2006). Defect cause modeling with decision tree and regression analysis, Turkey.

2- Mihails Savrasovs(2019) in the use of BlockChain technology in Cloud ERP systems "Engineering Sciences in Information Systems Management College of Transport and Communications in the College of Computer and Communications Sciences,pp 12.

3- Scholtz, B., \& Atukwase, D. (2016). An analysis of the perceived benefits and drawbacks of cloud ERP systems: a South African study. In Information Technology in Environmental Engineering, Springer, Cham.

4- Tadinen, H. (2005). Human resources management aspects of enterprise resource planning (ERP) systems projects. Helsinki, Finland: Swedish School of Economics and Business Administration,p7 .

5- Jenab, K., Staub, S., Moslehpour, S., \& Wu, C. (2019). Company performance improvement by quality based intelligent-ERP. Decision Science Letters, 8(2), 151-162

\section{B- Journals \&Periodicals}

1- Bankert, R. L., Hadjimichael, M., Kuciauskas, A. P., Thompson, W. T., \& Richardson, K. (2004). Remote cloud ceiling assessment using data-mining methods. Journal of Applied Meteorology, 43(12), pp1929-1946

2- Beleţ, T., \& Purcărea, A. ,2017, The Evolution of Enterprise Resource Planning Systems. International Journal of Advanced Engineering, Management and Science, 3(12),P 1091

3- Bokovec, K., Damij, T., \& Rajkovič, T. (2015). Evaluating ERP Projects with multi-attribute decision support systems. Computers in Industry, Slovenia.

4- Jenab and Staubb(2019) Improve company performance through the ERP system Quality-based smart adopting decision tree,United States of America

5- Menon, D. (2020). Critical Success Factors for ERP Projects: Recommendations from a Canadian Exploratory Study. International Journal of Business and Management, International Journal of Business and Management; Vol. 15, No. 2 ,p80.

6- Mishra, A., \& Mishra, D. (2011). ERP project implementation: evidence from the oil and gas sector. Acta Polytechnica Hungarica, 8(4)

TANMIYAT AL-RAFIDAIN (P-ISSN: 1609-591X; E-ISSN: 2664-276X) تنمية الرافدين 


\section{تصميم نموذج نظام مقترح لتخطيط موارد المشروع \\ الجبوري والجبوري}

7- Muscatello, Joseph R.\& Chen, Injazz J.,2008, Enterprise Resource Planning(ERP) Implementations: Theory And Practice, International Journal of Enterprise Information Systems, Volume 4, Issue 1, 65-77 ,p6467, http://zonecours.hec.ca

8- Pabedinskaite, A. (2010). Factors of successful implementation of ERP systems. Ekonomika ir vadyba, Vilnius Gediminas Technical University, Lithuania (15),p 275-283.

9- Sharma, H., \& Kumar, S. (2016). A survey on decision tree algorithms of classification in data mining. International Journal of Science and Research (IJSR), 5(4),p 2094

10- Sun, H., Ni, W., \& Lam, R. (2015). A step-by-step performance assessment and improvement method for ERP implementation: Action case studies in Chinese companies. Computers in Industry, 68, P 40-52.

11- Park, J. W., \& Lee, N. Y. (2006). A conceptual model of ERP for small and medium-size companies based on UML. IJCSNS International Journal of Computer Science and Network Security, 6(5A), 42-43.

\section{C- Conferences}

1- Ibrahim, Dr. Almahdi M. S,2010, What Organizations Should Know About Enterprise Resource Planning (ERP) System, Mediterranean \& Middle Eastern Conference on Information Systems April 12-13 , (EMCIS2010) AbuDhabi ,UAE,p8, http://www.iseing .org

2- Jafari, A. A., \& Nair, S. S. K. (2018, August). ERP Implementation in the Oil and Gas Sector: A Case Study in Sultanate of Oman. In 2018 7th International Conference on Reliability, Infocom Technologies and Optimization ,Trends and Future Directions

3- Wölfel, K., Smets, J. P., \& Strahringer, S. (2010, August). Automating erp package configuration for small businesses. In Proc. of IFIP International Conference on Research and Practical Issues of Enterprise Information Systems, Confenis, Natal/Brasil (pp. 25-27)

\section{D-Books}

1- Alter, Steven, 2002, Information Systems Foundation of E-Business,4th , Ed , Prentice Hall: New Jersey ,USA ,pp 93.

2- Bradford, M,2015, Modern ERP: Identifying, Implementing and Using Advanced Business Systems Today Poole College of North Carolina .

3- Kromann, F. M. (2018). Beginning PHP and MySQL: From Novice to Professional. Apress.

\section{E-Internet}

1- $\quad$ https://www.connectedpapers.com/ http://www.mysql.com 